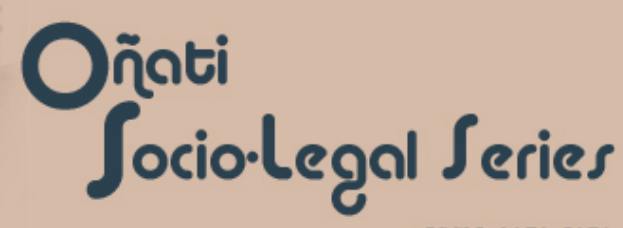

ISSN: 2079-5971

Oñati Socio-legal Series, v. 9, n. 4 (2019) - La institucionalización de la mediación: potencialidades y riesgos

ISSN: 2079-5971

\title{
La mediación en la gestión del impago de los préstamos y créditos hipotecarios en Cataluña: una institucionalización singular \\ (Mediation in Non-Payment of a Contract for Loan Mortgage in Catalonia: a Singular Institutionalization)
}

ISABEL VIOLA DEMESTRE*

Viola Demestre, I., 2018. La mediación en la gestión del impago de los préstamos y créditos hipotecarios en Cataluña: una institucionalización singular. Received 02 January 2018, Accepted 04 July 2018. Oñati Socio-legal Series [online], 9(4), 445-476. Available from: https://doi.org/10.35295/osls.iisl/0000-0000-0000-1090

\section{Resumen}

Este trabajo tiene como objetivo el análisis de la institucionalización que la mediación ha seguido en un contexto concreto, como es el derecho de consumo, y, en particular, en los conflictos generados a raíz del impago de la cuota de los préstamos o créditos hipotecarios, con el análisis de la normativa de la Unión Europea, estatal y autonómica de Cataluña. Asimismo, se estudia el proceso de mediación institucionalizado en las normas de consumo de Cataluña, para proteger el derecho a la vivienda de las personas en riesgo de exclusión residencial, porque alteran sustancialmente dos principios fundamentales (voluntariedad e imparcialidad y neutralidad) que suelen identificar este concreto mecanismo de gestión de conflictos, cuestionando si tal proceso puede seguir denominándose "mediación".

\section{Palabras clave}

Mediación; consumo; préstamo hipotecario; vivienda; mediación evaluativa

\begin{abstract}
The purpose of this paper is to analyze the institutionalization that mediation has followed in a specific context, such as consumer law, and, in particular, in the conflicts generated as a result of the non-payment of the mortgage loans or credits, with the analysis of the European Union, Spanish and autonomy of Catalonia regulations. Furthermore, the institutionalized mediation process is studied in the consumption norms of Catalonia about the protection of the right to housing of people at risk of residential exclusion, because they substantially alter two fundamental principles (voluntariety and impartiality and neutrality) that usually identify this concrete mechanism of conflict management, questioning whether such a process can continue to be called "mediation".
\end{abstract}

El trabajo forma parte de los estudios realizados en el seno del proyecto de investigación DER2015-63940-P.

* Profesora titular de Derecho civil de la Universidad de Barcelona. Doctora en Derecho (2000) y máster en Gestión y Resolución de Conflictos: Mediación (2002). Email: isabelviola@ub.edu. ORCID: https://orcid.org/0000-0002-3357-8808 


\section{Key words}

Mediation; consumption; mortgage loan; housing; evaluative mediation 


\section{Índice / Table of contents}

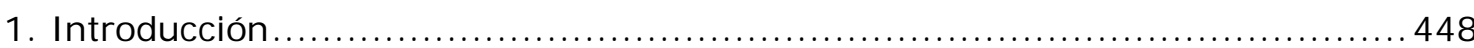

2. La institucionalización normativa de la mediación hipotecaria en Cataluña .....449

2.1. La normativa general de la Unión Europea en el ámbito general del consumo y de las ADR...

2.2. La regulación estatal de los ADR en materia de créditos hipotecarios:

el Sistema Arbitral de Consumo....

2.3. La regulación catalana: el Código de consumo y la legislación específica en el contexto hipotecario.

2.4. La regulación de la mediación en el ámbito hipotecario en Cataluña.

3. Los principios del proceso de mediación de conflictos de consumo

en materia de crédito o préstamo hipotecario: sus particularidades. 458

3.1. Principio de voluntariedad y mediación previa obligatoria en el Código de Consumo

3.2. Imparcialidad y neutralidad y la actuación del mediador en las Leyes para protección del derecho a la vivienda de las personas en riesgo de exclusión residencial.

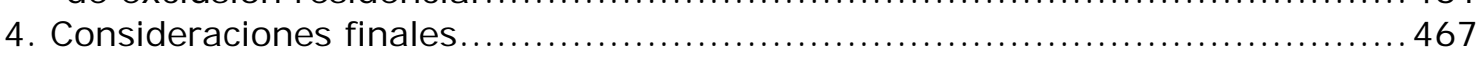

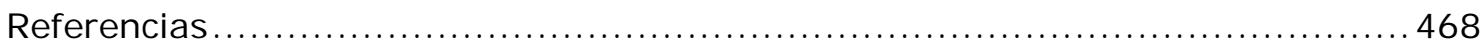

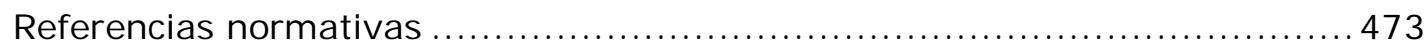

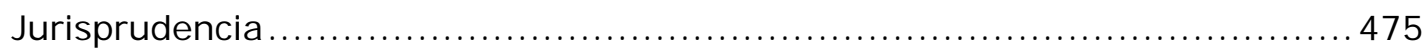




\section{I ntroducción}

Cataluña ha institucionalizado ${ }^{1}$ la mediación en el ámbito del derecho de consumo, en general y también en el ámbito del impago de las cuotas de los préstamos hipotecarios entre un consumidor y un empresario, en particular. Desde el año 2010, tiene su propio Código de Consumo, en virtud de la competencia exclusiva asumida ${ }^{2}$ y atribuida por el Estatuto de Autonomía de Cataluña de 2006 (artículo 123 de la Ley Orgánica 6/2006), de conformidad con el artículo 149.3 de la Constitución Española (en adelante, CE), en el cual la mediación se ofrece como uno de los "sistemas operativos de resolución voluntaria de conflictos y de reclamaciones en materia de consumo" (art. 131-1 del Código de consumo de Cataluña, en adelante, CConsum).

En este marco competencial del derecho de consumo, el Parlamento catalán ha venido promulgando varias normas con el objetivo de paliar los problemas que afectan a la vivienda habitual de las personas debido a su sobreendeudamiento, motivado, en los últimos tiempos, por los efectos de la crisis económica-financiera que se inició en 2007 (Recarte 2008, 27-73, García Montalvo 2008, Tortella y Núñez 2009, Bel i Queralt y Estruch Manjón 2009, 50-57, Embid I rujo 2009, Sosa Wagner y Fuertes 2011, Laparra y Pérez Eransus 2012, Berrocal Lanzarot 2012, 493-494, Díez García 2012, 18-71). Entre otras medidas, se ha institucionalizado la mediación, también, en este sector hipotecario.

Con carácter general, la regulación de este mecanismo de gestión de conflictos se contiene en el ya citado Código de consumo y en el Decreto 98/2014 sobre el procedimiento de mediación en las relaciones de consumo ${ }^{3} \mathrm{y}$, de modo especial, para evitar la exclusión residencial, en la Ley 20/2014, de 29 de diciembre, de modificación de la Ley 22/2010, de 20 de julio, del Código de consumo de Cataluña, para la mejora de la protección de las personas consumidoras en materia de créditos y préstamos hipotecarios, vulnerabilidad económica y relaciones de consumo; la Ley 24/2015, de 29 de julio, de medidas urgentes para afrontar la emergencia en el ámbito de la vivienda y la pobreza energética y, la más reciente, la Ley 4/2016, de 23 de diciembre, de medidas de protección del derecho a la vivienda de las personas en riesgo de exclusión residencial.

El fundamento de esta regulación se halla en la legislación de la Unión Europea, a la que vamos a mencionar seguidamente, que pretende, de un lado, fomentar el uso de las Alternative Dispute Resolution (ADR) ${ }^{4}$ en la resolución de los conflictos entre un consumidor y un empresario y, de otro lado, en un contexto más concreto, instar a que los Estados miembros adopten medidas para evitar que los consumidores puedan perder su vivienda habitual al no poder hacer frente al pago de la cuota de su préstamo hipotecario por circunstancias sobrevenidas (apartado 2).

Una vez justificado el fundamento de esta institucionalización en el derecho europeo, estatal y catalán de consumo, nos queremos detener en el proceso de mediación

\footnotetext{
${ }^{1}$ En este texto, el sustantivo institucionalización se entiende en el sentido de regulación o, en palabras del Diccionario de la Lengua Española, en la 6a acepción del vocablo institución (a la que remite la entrada relativa a institucional), "la colección metódica de los principios o elementos de una ciencia, de un arte, etc". (además de la 1 ạ acepción, esto es, "establecimiento o fundación de algo"; véase en http://dle.rae.es/?id=LnOUwtU). La mediación es una institución jurídica entendida como el conjunto de disposiciones de derecho relativas a las relaciones jurídicas de una clase determinada o el conjunto de normas coordinadas para la regulación de las singulares relaciones típicamente previstas por el ordenamiento jurídico. En otro sentido, también se entiende por institucionalización cualquier entidad ( pública o privada) que, como tal entidad, adopte procedimientos de ADR como parte de hacer negocios (por ejemplo, escuelas que desarrollan programas de mediación entre pares, tribunales que establecen reglas para gobernar la remisión a los procedimientos de ADR y agencias gubernamentales que incorporan procesos de ADR en el desarrollo de reglas y regulaciones). Es el concepto de Press 1997, p. 904.

${ }^{2}$ El Estado mantiene la "cláusula residual" del artículo 149.3 de la Constitución Española (en adelante, CE).

3 Este Decreto da cumplimiento a la Directiva 2013/11/UE, de 21 de mayo, relativa a la resolución alternativa de litigios en materia de consumo, y el Reglamento UE/524/2013, de 21 de mayo, sobre resolución de litigios en línea en materia de consumo.

${ }^{4}$ Recordemos que ADR se suele traducir, en castellano, como Resolución Alternativa de Disputas.
} 
específico previsto en las normas catalanas para la gestión de los conflictos hipotecarios. De la lectura de los distintos preceptos que lo regulan se pueden apreciar algunas particularidades significativas en relación con los principios básicos que identifican la mediación como tal proceso, como son la voluntariedad, de un lado, y la imparcialidad y neutralidad del mediador, del otro (apartado 3). Vamos a poner de manifiesto, de una parte, la existencia de una mediación preceptiva en el Código de Consumo de Cataluña antes de interponer la demanda de ejecución por impago de cuota del préstamo cuyo cumplimiento se garantiza con un inmueble que es la vivienda habitual del consumidor prestatario y, de otro, de la actuación de la persona mediadora que impone una solución, en los términos previstos en la legislación promulgada a tal efecto.

\section{La institucionalización normativa de la mediación hipotecaria en Cataluña}

Para una mayor comprensión de cuál es la situación actual, es importante conocer el contexto en el que se ha desarrollado la regulación de la mediación en el ámbito del consumo, en general, y en un sector específico, como es el hipotecario, en particular en Cataluña. Y ello es así en atención a que el contrato de préstamo o crédito con garantía hipotecaria para la adquisición de la vivienda habitual es un producto financiero que se sitúa en el marco de las denominadas relaciones de consumo entre un consumidor (el comprador de la vivienda, prestatario; también un avalador) y un empresario (entidad financiera, prestamista), por tanto, sujeto a las normas jurídicas especializadas del derecho de consumo (Barral Viñals 2012, p. 473).

Hay que indicar que la mediación institucionalizada, prevista en un sistema público de servicios de mediación en consumo, coexiste con la denominada mediación privada, llevada a cabo dentro del marco de las asociaciones de consumidores u organizaciones de personas consumidoras, entidades sin finalidad de lucro dedicadas a la representación y defensa de los derechos de los consumidores y usuarios y, en estas tareas, les proporciona representatividad en ciertos organismos públicos (art. 23 del Real Decreto Legislativo 1/2007, de 16 de noviembre, por el que se aprueba el texto refundido de la Ley General para la Defensa de los Consumidores y Usuarios y otras leyes complementarias). Por su parte, el Código de Consumo de Cataluña también las entidades que pueden tener la consideración de organizaciones de personas consumidoras (art. 127-2 CConsum) a las que atribuye, entre otras funciones, "la gestión de los conflictos en materia de consumo, especialmente por medio de la mediación" (art. 127-4 CConsum). La calidad de las entidades de resolución alternativa de litigios en materia de consumo vendrá determinada por el cumplimiento de los requisitos establecidos en la Ley 7/2017, de 2 de noviembre.

En este apartado 2, el objetivo es ofrecer la génesis de las normas principales que han institucionalizado jurídicamente este procedimiento de mediación en este ámbito específico que es el derecho de consumo ${ }^{5}$ y que serán objeto de estudio.

Para ello, vamos a mostrar, en primer lugar, el panorama general de la normativa básica promulgada por la Unión Europea, baluarte de la defensa de los intereses de los consumidores y usuarios, con el consabido reflejo de las mismas en las normas en España. En un segundo epígrafe, se mencionará la regulación del procedimiento de resolución alternativa de litigios en materia de consumo, esto es, el sistema arbitral de consumo estatal, de conformidad con el Real Decreto 231/2008 y en un tercer apartado, se concretan las leyes dictadas por el Parlamento catalán sobre la mediación en conflictos derivados por el impago de las cuotas de los préstamos hipotecarios y por sobreendeudamiento que afectan a la vivienda habitual.

\footnotetext{
${ }^{5}$ La mediación en consumo es una categoría legal puesto que se da cuando un consumidor tiene un conflicto en relación con una empresa o un profesional, como relación de consumo, definida y regulada por un marco normativo específico. El análisis de la mediación en consumo parte de este hecho ya que sólo aquellos conflictos que puedan ser calificados como relaciones de consumo podrán acudir al mecanismo de la mediación en consumo (Barral y Suquet 2010, p. 307, Orozco Pardo 2016, p. 671).
} 
2.1. La normativa general de la Unión Europea en el ámbito general del consumo y de las ADR

La Unión Europea siempre se ha mostrado predispuesta a establecer y desarrollar sistemas extrajudiciales de resolución de conflictos en el ámbito de consumo. En este sentido, y de un tiempo a esta parte, viene incluyendo en cada uno de sus distintos actos jurídicos en materia de consumidores un artículo con el propósito de velar, promover y fomentar el uso de los mecanismos de resolución extrajudicial de litigios en el ámbito del derecho de los consumidores. Sirvan como muestra los artículos 20 y 21 de la Directiva 2002/21/CE, de 7 de marzo de 2002, de los servicios de comunicaciones electrónicas; los artículos 17 y 19 de la Directiva 2000/31/CE, de 8 de junio de 2000, relativa a determinados aspectos jurídicos de los servicios de la sociedad de la información, en particular el comercio electrónico en el mercado interior; art. 14 de la Directiva 2002/65/CE, de 23 de septiembre de 2002, relativa a la comercialización a distancia de servicios financieros destinados a los consumidores; art. 11 de la Directiva 2002/92/CE, de 9 de diciembre de 2002 sobre la mediación en los seguros; art 53 de la Directiva 2004/39/CE, de 21 de abril de 2004 sobre el mercado de instrumentos financieros; el art. 24 de la Directiva 2008/48/CE, de 23 de abril de 2008, sobre crédito al consumo; el art. 14. 2 de la Directiva 2008/122/CE del Parlamento europeo y del Consejo, de 14 de enero de 2009, relativa a la protección de los consumidores con respecto a determinados aspectos de los contratos de aprovechamiento por turno de bienes de uso turístico, de admisión de productos vacacionales de larga duración, de reventa y de intercambio; el apartado f) de punto 1 del Anexo (medidas de protección del consumidor) de la Directiva 2009/72/CE, de 13 de julio de 2009, sobre normas comunes para el mercado interior de la electricidad. Entre estos sistemas se halla, sin duda, la mediación.

La justificación de esta proliferación de normas hay que encontrarla en el fundamento de los procedimientos de resolución alternativa de conflictos: junto al procedimiento judicial estos mecanismos, también, son medios de acceso a la justicia. Ante los obstáculos de los consumidores en obtener una reparación de los daños sufridos a raíz de la compra o del uso de productos defectuosos o como consecuencia de servicios insuficientes (Resolución del Parlamento Europeo de 13 de marzo de 1987, reiterada por el Consejo de Europa, en su Resolución de 25 de junio de 1987 sobre acceso de los consumidores a la justicia) ${ }^{6}$ se reconoce el derecho de acceso a la justicia de los consumidores con los medios o procedimientos "adecuados", que sean rápidos, eficaces y poco onerosos, con los que atender estas reclamaciones, en general, de escasa o pequeña cuantía y, en las últimas décadas, respecto de bienes y servicios adquiridos en línea o en otros países de la Unión Europea, lo que significa que los juzgados y tribunales no son una opción óptima para formular estas reclamaciones.

En este escenario y para evitar que los consumidores renunciasen a reclamar sus derechos por la ineficiente vía judicial, se buscaron otras vías de reclamación, al margen de los juzgados y tribunales. Desde los primeros trabajos, con el Libro Verde de la Comisión, de 16 de noviembre de 1993, sobre el acceso de los consumidores a la justicia y solución de litigios en materia de consumo en el mercado único, esta voluntad incidió en la normativa promulgada por la Unión Europea hasta la actual Directiva 2013/11/UE del Parlamento Europeo y del Consejo, de 21 de mayo de 2013 por la que se modifica el Reglamento (CE) no 2006/2004 y la Directiva 2009/22/CE (en adelante, Directiva ADR 2013/11/UE) ${ }^{7}$ y el Reglamento (UE) № 524/2013, del

\footnotetext{
${ }^{6}$ La Resolución de Consejo de 25 de junio de 1987 fue fruto de la Comunicación 84/692 emitida por la Comisión que afirmó que "el objetivo global sigue estando claro: garantizar que, en toda la comunidad, los consumidores puedan obtener un nivel de reparación idéntico en su conjunto". Sobre acceso de los consumidores a la justicia y solución de litigios en materia de consumo en el mercado único, el Libro Verde, 16 de noviembre de 1993, núm. COM (93) 576 final. p. 9 (en adelante, Libro Verde de Consumo).

7 La Directiva 2013/11/UE es de aplicación a los servicios financieros. Así de taxativos se mostraron algunos consejeros del Consejo Económico y Social en el voto particular que emitieron del Dictamen
} 
Parlamento Europeo y del Consejo de 21 de mayo de 2013 por la que se modifica el Reglamento (CE) no 2006/2004 y la Directiva 2009/22/CE (en adelante, Reglamento ODR de consumo) ${ }^{8}$ actos legislativos por medio de los cuales se reviste de carácter imperativo a los principios rectores de los procedimientos ADR/ODR, respectivamente, en materia de consumo en la UE.

Un año más tarde, se aprueba la Directiva 2014/17/UE, acto legislativo que, aunque tiene como objetivo orientar a los jueces para que puedan decidir las controversias relativas a los contratos de créditos garantizados con bienes de uso residencial, en su artículo 39 pretende también fomentar el recurso a los procedimientos alternativos a la vía judicial de solución de las controversias que puedan surgir en estos contratos de créditos hipotecarios.

Hasta aquí hemos relatado la institucionalización normativa de la mediación en el ámbito del consumo en general y en el contexto hipotecario, en concreto, por parte de la Unión Europea. Veamos cómo se ha llevado a cabo en el ordenamiento jurídico estatal y catalán.

2.2. La regulación estatal de los $A D R$ en materia de créditos hipotecarios: el Sistema Arbitral de Consumo

El Proyecto de Ley reguladora de los contratos de crédito inmobiliario, de 14 de noviembre de 2017, prevé dos vías de resolución de los conflictos que puedan surgir respecto de los créditos hipotecarios del ámbito de la Ley: de un lado, un procedimiento que se inicia de mutuo acuerdo o por adhesión al Sistema Arbitral de Consumo $u$ otros sistemas ADR similares que figuren en la lista que publica la Comisión Europea y que cumplan los requisitos establecidos en la Ley $7 / 2017 ;{ }^{9}$ de otro lado, un mecanismo que comienza a instancia del prestatario, por tanto, unilateral, de protección de los clientes de servicios financieros.

De todos ellos, nos vamos a ocupar de los procedimientos ya vigentes en los que la mediación se prevé como proceso de resolución de estos concretos litigios. Este primer mecanismo que se propone para gestionar los conflictos de consumo con entidades financieras, el Sistema Arbitral de Consumo, ya existe; no es un procedimiento creado a raíz de esta Directiva 2014/17/UE. El Sistema Arbitral de Consumo es el arbitraje institucional de resolución extrajudicial, de carácter vinculante y ejecutivo para ambas partes, de los conflictos surgidos entre los consumidores o usuarios y las empresas o profesionales en relación a los derechos legal o contractualmente reconocidos al consumidor (art. 1.2 RD 231/2008, de 15 de febrero).

Los órganos encargados de la administración de este arbitraje institucional son las Juntas Arbitrales de Consumo (nacional, de ámbito autonómico, provincial, mancomunidad y municipal), de carácter permanente y dependientes de la Administración Pública, que han sido acreditadas por la Unión Europea puesto que cumplen con los principios de independencia, transparencia, contradicción, eficacia, legalidad, libertad y representación, aplicables a los órganos responsables de la

5/2015 aprobado en la Sesión extraordinaria del Pleno de 5 de mayo de 2015. Véase la p. 19. Estos consejeros están en desacuerdo con que la disposición adicional cuarta del Anteproyecto de Ley ADR se establezca que para el sector financiero solo será acreditada una única entidad "que habrá de ser constituida por Ley".

8 Por medio del Reglamento se establece la creación de una plataforma gratuita de resolución de litigios en línea (en adelante, plataforma RLL). Esta plataforma adopta la forma de un sitio web interactivo y multilingüe y ofrece a los consumidores y a los comerciantes una ventanilla única para la resolución extrajudicial ODR mediante entidades de resolución alternativa que están vinculadas a dicha plataforma. La plataforma realiza la labor de auxiliar la reclamación a la entidad competente (Barral Viñals 2014, p. 404). En el Reglamento se establece que para que la plataforma RLL funcione se requiere primero contar con entidades de resolución alternativa que cumplan con los requisitos de calidad establecidos en la Directiva ADR. Con excepción de algunas de sus disposiciones, el Reglamento es aplicable desde el 9 de enero de 2016.

${ }^{9}$ Sobre una primera valoración del Anteproyecto de esta ley, véase Anderson 2016, p. 63. 
resolución extrajudicial de litigios en materia de consumo que proponen o imponen una solución, previstos, en su día, en la Recomendación 98/257/CE y, normativamente, en la Directiva 2013/17/UE, pendiente de transposición.

Este sistema se caracteriza, en primer lugar, por su unidireccionalidad y por unos principios específicos. Es unidireccional pues solo los consumidores y usuarios están legitimados para instar el inicio del arbitraje de consumos (art. 57.1 TR Ley 1/2007), aunque el empresario o profesional puede reconvenir en el seno del procedimiento arbitral (art. 41.1 RD 231/2008). Los principios específicos son el de audiencia, contradicción, igualdad de las partes y gratuidad (salvo el coste, en determinados casos, del peritaje a instancia de una o de ambas partes), ${ }^{10}$ según dispone el artículo 41 RD 231/2008, configurándose como un sistema ventajoso por su rapidez (en los plazos para dictar laudo y en su posible resolución por medios electrónicos). Además, debe cumplir con los principios establecidos en la Ley 7/2017, de 2 de noviembre.

Este sistema de resolución de controversias derivadas de relaciones de consumo (Marín López 2008, p. 5), que atiende las reclamaciones de cualquier cuantía, ${ }^{11}$ tiene escasa implantación (Blanco García 2015a, p. 97) en el sector financiero. ${ }^{12}$ Algunas asociaciones de consumidores y usuarios de entidades bancarias proponen algunas medidas encaminadas a que estas empresas financieras se vayan incorporando a este sistema. ${ }^{13}$

Y es que el acceso a este sistema arbitral es voluntario (exposición de motivos, párrafo 8, RD 231/2008) a través del convenio arbitral, que se alcanza por dos vías:

a) el mutuo acuerdo de las dos partes, manifestado en una cláusula contractual de sumisión al arbitraje de consumo o en un convenio aparte, para el caso de que surjan controversias entre ellas o también en caso de no existir dicha cláusula contractual o convenio separado, el consumidor presenta la solicitud de arbitraje de consumo y el empresario la acepta (art. 24.4 y 37.3.b) del RD 231/2008). ${ }^{14}$

b) la oferta unilateral de adhesión al sistema arbitral de consumo que realiza el empresario o profesional (art. 25.1.I RD 231/2008) [Marín López 2008, p. 10] que valida formalmente como convenio cuando el consumidor presenta su solicitud siempre que coincida con el ámbito de la oferta.

Por consiguiente, en el ámbito particular del crédito hipotecario, las entidades financieras tienen la opción de adherirse o no al sistema o, en caso de no estar adheridas, igualmente tienen la facultad de aceptar o no la iniciativa de un consumidor de gestionar la resolución de un determinado conflicto a través de este sistema.

En este aspecto, nos cuestionamos hasta qué punto esta voluntariedad que caracteriza el sistema arbitral de consumo regulado en el RD 231/2008 español está incumpliendo el mandato de la Directiva 2014/17/UE sobre créditos hipotecarios en la cual se puede leer que "Ios Estados miembros deben garantizar que la participación de prestamistas e intermediarios de crédito en este tipo de procedimientos de

\footnotetext{
${ }^{10}$ Acerca de la gratuidad del arbitraje de consumo y de los costes de algunas pruebas de las partes, véase Marín López 2008.

11 Ámbito objetivo del RD 231/2008: son susceptibles de arbitraje de consumo los conflictos que versen "sobre materias de libre disposición de las partes conforme a derecho" (art. 2.1 RD 231/2008; art. 2.1 Ley de Arbitraje), salvo aquellos que versan sobre intoxicación, lesión, muerte o existen indicios racionales de delito (art. 57.1 TR Ley 1/2007) y la responsabilidad civil por daños y perjuicios directamente derivados de estos hechos (art. 2.2 TRD 231/2008) [Marín López 2008].

12 En palabras de ADICAE, la adhesión de los bancos al sistema es prácticamente "nula". Véase en ADICAE S.f.

${ }^{13}$ ADICAE propone tres medidas: una incorporación progresiva de las entidades financieras, con una adhesión limitada por las materias y cuantías, para ir aumentándolas gradualmente a medida que estas fueran confiando en el sistema arbitral de consumo; el establecimiento de fuertes incentivos fiscales para las entidades que se adhieran a él y, en tercer lugar, que el procedimiento previsto en el RD 231/2008 sea también bidireccional, esto es, que también pudiera ser iniciado por el empresario.

14 Téngase en cuenta, además, lo establecido en el artículo 15 de la Ley 7/2017 sobre la eficacia de los pactos previos entre consumidor y empresario.
} 
resolución alternativa de litigios no sea facultativa". Lo que ocurre es que no lo prevé una norma sino que se incluye en un considerando (el 77) cuya finalidad es motivar de modo conciso las disposiciones esenciales de la parte dispositiva sin reproducir ni parafrasear su texto, sin incluir disposiciones de carácter normativo, destinados, eso sí, a la buena comprensión de la parte dispositiva, o para el control de la legalidad como recordatorio del contenido esencial de otras disposiciones distintas de la base jurídica (Servicio Jurídico de la Unión Europea 2013), aunque pueden enunciarse algunas normas básicas de la motivación (Servicio J urídico de la Unión Europea 2013, p. 31). Tal vez, esta obligatoriedad se consiga con la creación de una única entidad, acreditada por la autoridad competente en los términos establecidos en los artículos 26 y siguientes de la Ley 7/2017, mediante una ley que, además, obligará a las entidades financieras a participar en los procedimientos en dicha entidad de resolución alternativa de litigios para este ámbito estratégico ${ }^{15}$ de actividad, de conformidad con lo establecido en su Disposición Adicional Primera.

A la voluntariedad de la adhesión o no a este procedimiento previsto en el sistema arbitral de consumo por parte de los consumidores y las entidades financieras, hay que resaltar, además, la voluntariedad de acudir a una fase previa antes de que el árbitro dicte su laudo, que es la mediación, como así se desprende de la rúbrica del art. 38 RD 231/2008 y de los artículos $37.3^{16}$ y 49.1.1 ${ }^{17}$ de la misma norma.

La mediación de consumo en este sistema arbitral (Blanco Carrasco 2009, p. 143) se rige por la legislación sobre la materia que resulte de aplicación (art. 38.2 RD $231 / 2008$ ), que será la autonómica, en congruencia con la competencia plena de las Comunidades Autónomas para regular la mediación en consumo ${ }^{18}$ y atribuir la función de mediador a algún órgano administrativo (Marín López 2008, p. 20). Seguidamente analizaremos el procedimiento específico de mediación. Antes, queremos poner de manifiesto que, además de este procedimiento institucionalizado de gestionar los conflictos a través del Sistema Arbitral de Consumo, también existe la posibilidad de acudir a procesos de mediación, privados (García Montoro 2015, p. 16), llevados a cabo por asociaciones de mediación. Y esta posibilidad ha quedado reforzada, en el ámbito estatal, con la citada Ley 7/2017 que ha suprimido el apartado d) del artículo 2.2 de la Ley 5/2012, de 6 de julio, de mediación en asuntos civiles y mercantiles (en adelante, LMACM), que excluía de su aplicación la mediación en materia de consumo. Con esta eliminación, la mediación de consumo puede tener lugar en el marco de la regulación institucionalizada del Sistema arbitral de consumo del RD $231 / 2008$, por un lado, y las normas de la LMACM, por otro lado.

\subsection{La regulación catalana: el Código de consumo y la legislación específica en} el contexto hipotecario

La institucionalización de la mediación en consumo en Cataluña proviene, en gran medida, del proceso que ha seguido este procedimiento en el acervo comunitario y el Real Decreto 231/2008, de 15 de febrero, por el que se regula el Sistema Arbitral de Consumo mencionado, que prevé la mediación como una fase del procedimiento arbitral.

\footnotetext{
15 "ADR is mandatory in certain sectors where there is a high risk of consumer detriment or complex disputes, with a single public body operating as an ombudsman in some of these sectors (e.g. financial services, legal services), and several private ADR bodies operating in others (e.g. telecommunications and estate agents). In this latter category, businesses have to refer unresolved complaints to an ADR provider, but they have a choice of which ADR provider they sign up to use." Así reza el informe sobre las ADR y ODR en consumo de Gran Bretaña, del Department for Business Innovation \& Skills (2014), punto 7, pp. 15 y 16.

${ }^{16}$ Este artículo 37.1 RD 231/2008 dispone que en la resolución que acuerde el inicio del arbitraje conste de forma expresa la invitación a las partes a alcanzar un acuerdo a través de la mediación, de lo cual se deduce que esta podrá tener lugar, si es el caso, una vez el procedimiento arbitral ha comenzado.

${ }^{17}$ El artículo 49.1.I RD 231/2008 obliga a suspender el computo del plazo para dictar el laudo si se intenta la mediación previa.

${ }^{18}$ Competencia reconocida en la Exposición de Motivos del RD 231/2008.
} 
De acuerdo con la competencia legislativa de Cataluña, anteriormente mencionada, ${ }^{19}$ se promulga la Ley 22/2010, de 20 de julio, del Código de consumo de Cataluña, que da cumplimiento a algunas de las Directivas de la Unión Europea en esta materia (Preámbulo de la Ley 22/2010, de 20 de julio, del Código de consumo de Cataluña), en cuyo título III se establece la regulación de los métodos extrajudiciales de resolución de conflictos entre los cuales se halla la mediación y que el Decreto 98/2014 desarrolla.

A continuación nos vamos a ocupar de la institucionalización que reglamenta este procedimiento extrajudicial de gestión de conflictos en un sector específico, como es el hipotecario, relativo, particularmente, a las controversias generadas por el impago de las cuotas del préstamo que, en caso de culminar el procedimiento de ejecución hipotecaria, puede suponer la pérdida de la vivienda habitual al prestatario hipotecario o fiador.

\subsection{La regulación de la mediación en el ámbito hipotecario en Cataluña}

Una de las respuestas a la crisis económica y financiera que comenzó en 2007 y que afectó en España ${ }^{20}$ a ciudadanos que no podían cumplir con su deuda hipotecaria fue el recurrir a servicios de mediación (Ceballos 2013, p. 23). Su principal objetivo: proporcionar ayuda al propietario de una vivienda que se encontraba en una situación, principalmente ${ }^{21}$ de sobreendeudamiento que corría el riesgo de perderla en un proceso de ejecución. ${ }^{22}$

El gobierno catalán fue pionero entre estas iniciativas públicas, por medio de Ofideute, ${ }^{23}$ que depende de la Agencia de la Vivienda de Cataluña, ofreciendo un servicio de mediación en el ámbito hipotecario. En esta misma línea, podemos encontrar el Servicio de Mediación Hipotecaria del Gobierno Vasco, que la incluye entre sus servicios de justicia. ${ }^{24}$ También se emprendieron iniciativas en el ámbito privado, como Cáritas Diocesana de Barcelona. ${ }^{25}$

La profesión legal no podía ignorar este problema y, a partir de su sensibilidad social, se puso en marcha, en enero de 2012, la primera Oficina de Intermediación Hipotecaria, en Terrassa, ciudad próxima a Barcelona que tenía, por aquel entonces, una población de 214.000. El servicio fue el resultado de un acuerdo entre el Ayuntamiento de la ciudad y el Ilustre Colegio de Abogados de Terrassa. ${ }^{26}$ Después

\footnotetext{
19 Las comunidades autónomas han promulgado normas reguladoras del ámbito del consumo. Pueden consultarse en el sitio web de la Agencia española de consumo, seguridad alimentaria y nutrición (http://www.aecosan.msssi.gob.es).

${ }^{20}$ Esta situación de crisis afectó a distintos países del mundo de forma dispar. En los Estados Unidos de América, se promovió de manera relevante la creación de programas de mediación hipotecaria (foreclosure mediation), precisamente, con el objetivo de crear y llevar a cabo una campaña de concienciación pública para alentar a los prestatarios a ponerse en contacto con su prestamista si se enfrentan a renegociación o si tienen problemas para realizar el pago de su deuda. Distintos Estados instituyeron sus propios programas de mediación, publicitados en la National Consumers Law Center (https://www.nclc.org/issues/foreclosure-mediation-programs-by-state.html). Como ejemplo, véase la experiencia del estado de Ohio en Hagerott 2012, pp. 900 a 902.

21 En un número inferior, la crisis también sacudió a los avalistas que habían hipotecado su propio patrimonio para garantizar deuda ajena, en un porcentaje elevado de casos, de los hijos o familiares.

${ }^{22}$ Las estadísticas sobre ejecuciones hipotecarias, véase Rodríguez López 2014, pp. 106-110.

23 Ofideute es el nombre del organismo que atiende los ciudadanos que se hallan en una situación de sobreendeudamiento al que les ofrece la mediación como procedimiento para poder encontrar opciones al impago de su deuda. Para más información, véase la siguiente web: http://www.agenciahabitatge.cat/wps/portal?WCM_GLOBAL_CONTEXT=ca/ahc/web/serveis/ciutada/ofid eute.

${ }^{24}$ Acerca del Servicio de Mediación del País Vasco, véase la web http://www.justizia.net/mediacionhipotecaria.

25 Para más información sobre el Servicio de mediación hipotecaria de Cáritas Diocesana, véase https://caritas.barcelona/es/sin-hogar-y-vivienda/servicio-de-mediacion-en-vivienda/.

${ }^{26}$ Sobre este servicio en Terrassa, véase https://aoberta.terrassa.cat/oficines/infoEntitat.jsp?id=17757.
} 
esta primera oficina municipal, otras administraciones autonómicas ${ }^{27}$ y locales abrieron los servicios de mediación, algunas de ellas por el despliegue de la Diputación Provincial. ${ }^{28}$ En estas oficinas abogados ofrecen pro bono, información, asesoramiento y apoyo a las personas que están luchando para cumplir con los pagos de la hipoteca y están en riesgo de perder su casa. El proceso facilita la comunicación entre el deudor y el prestamista para encontrar una solución antes o incluso durante el proceso de ejecución hipotecaria. ${ }^{29}$

En general, el objetivo principal de estos servicios públicos y también privados es preparar una propuesta a medida de las necesidades específicas de la unidad familiar, que debe cumplir unos requisitos objetivos y subjetivos específicos, y lo presentará a la institución financiera. Todos son ejemplos de intervención institucional, donde los diferentes niveles de la administración pública (local, el ayuntamiento de la ciudad y los gobiernos autonómicos) han actuado en el orden público económico sólo para ofrecer a la parte más débil (el propietario, el prestatario) de una solución negociada con la otra (el prestamista, la entidad financiera). También desde el sector privado (asociaciones de consumidores) se han desarrollado experiencias de mediación con el mismo propósito.

La Unión Europea también se mostró sensible ante esta situación de eventual pérdida de la vivienda en ejecución de un proceso iniciado como consecuencia del incumplimiento de la deuda. En el documento de trabajo de la Comisión, del 31 de marzo de 2011, titulado National measures and practices to avoid foreclosures procedures for residential mortgage loans. Accompanying document to the Proposal for a Directive of the European Parliament and of the Council on credit agreements relating to residential property se recogen las medidas que los estados miembros de la Unión Europea adoptaron a nivel nacional, entre abril de 2009 y septiembre de 2010, para hacer frente a los impagos de las cuotas de los préstamos hipotecarios (Lauroba 2012, p. 127). Este documento, como su título indica, acompañaba la propuesta de Directiva sobre los contratos de crédito celebrados con los consumidores para bienes inmuebles de uso residencial que constituye la Directiva 2014/17/UE del Parlamento Europeo y del Consejo, de 4 de febrero de 2014. ${ }^{30}$

A los efectos de la resolución extrajudicial de conflictos, esta Directiva 2014/17/UE es relevante por dos previsiones legislativas. La primera, por cuanto que propone a los Estados miembros que adopten medidas para alentar a los prestamistas a mostrarse razonablemente tolerantes ${ }^{31}$ antes de iniciar un procedimiento de ejecución (art. 28 Directiva 2014/17/UE). Intentar alcanzar un acuerdo con el prestatario, a través del procedimiento de mediación, por ejemplo, sería una medida que trataría de evitar el inicio del procedimiento judicial que puede terminar con la pérdida de la vivienda del titular de la garantía. La segunda, porque se insta a los Estados miembros para que velen por el establecimiento de procedimientos adecuados y efectivos de reclamación y recurso para la resolución extrajudicial de los litigios de los consumidores con prestamistas, intermediarios de crédito y representantes designados en relación con contratos de crédito, valiéndose, si procede, de organismos ya existentes (art. 38 Directiva 2014/17/UE).

27 Es el caso de Aragón, que también ofrece un programa de mediación hipotecaria: http://www.aragon.es/DepartamentosOrganismosPublicos/Departamentos/VertebracionTerritorioMovilid adVivienda/AreasTematicas/ViviendaRehabilitacion/ci.04_Programa - Mediaci\% C3\% B3n -

Hipotecaria. detalleDepartamento.

${ }^{28}$ A título de ejemplo, el Servicio de la localidad de Santa Perpetua de Mogoda, presentado en mayo de 2017, en el marco del despliegue que viene realizando la Diputación de Barcelona (Viladomat 2017).

${ }^{29} \mathrm{El}$ importante papel de los abogados se puede ver en la página web Consejo General de la Abogacía española donde el deudor con problemas de pago hipotecario puede encontrar una Oficina de Mediación de Ejecuciones Hipotecarias en diferentes ciudades de España. Información disponible en http://www.abogacia.es/2012/06/21/oficina-de-intermediacion-hipotecaria/.

30 Sobre los servicios de mediación para gestionar la situación de sobreendeudamiento del consumidor en distintos países de la Unión Europea, véase Tamayo Haya 2010, p. 248, p. 254 y siguientes.

${ }^{31}$ La cursiva es nuestra. Sin duda, se trata de una expresión que merece un análisis particular sobre qué medidas pueden adoptar los acreedores hipotecarios que se ajusten a la finalidad de la Directiva. 
El legislador catalán da cumplimiento al mandato de la Directiva 2014/17/UE al establecer un procedimiento de gestión de conflictos que persigue esta finalidad (Nasarre y Simón 2015). Se incluye la mediación en la modificación del Código de Consumo introducida por la Ley 20/2014. ${ }^{32}$ Y lo hace en dos sentidos: de un lado, se establece que las administraciones públicas catalanas garanticen que, en los casos de ejecución hipotecaria de la vivienda habitual como consecuencia del incumplimiento del deudor, pueda llevarse a cabo un procedimiento de mediación destinado a la resolución extrajudicial de conflictos previo a cualquier otro procedimiento judicial o a la intervención notarial con la finalidad de buscar "acuerdos entre las partes que hagan viable que la persona consumidora conserve la propiedad de la vivienda o, subsidiariamente, la posibilidad de mantener su uso y disfrute". De otro lado, ha establecido una mediación preceptiva: las partes en conflicto, antes de interponer cualquier reclamación administrativa o demanda judicial, deben acudir a la mediación o pueden acordar someterse al arbitraje. Si transcurridos tres meses a contar de la notificación del acuerdo de inicio de la mediación no se ha alcanzado un acuerdo satisfactorio, cualquiera de las partes puede acudir a la reclamación administrativa o a la demanda judicial. Se trata, pues, de un proceso obligatorio previo, a instancias únicamente del prestatario consumidor, ${ }^{33}$ que no tuvo su correspondiente incorporación en la LEC (Pérez Daudí 2015, p. 5).

La Ley 20/2014 viene a respaldar las prácticas de mediación que se estaban llevando a cabo por diferentes agentes (la administración pública, las asociaciones de consumidores o los colegios profesionales, etc.) para renegociar los préstamos 0 créditos hipotecarios con las entidades financieras (Barral Viñals 2015, p. 3).

El legislador catalán también recurre a la mediación como mecanismo extrajudicial de resolución de situaciones de sobreendeudamiento derivado de relaciones de consumo. En primera instancia, regula este procedimiento en la Ley 24/2015 (art. 2; disposición final quinta) ${ }^{34}$ y, a raíz del recurso de inconstitucionalidad interpuesto contra ella que ha significado la suspensión de la aplicación de varios de sus artículos, también la prevé en la Ley 4/2016 [art. 3. a); art. 8, apartados a), c) i d); art. 9; arts. 10 a 14; art.17; disposición adicional segunda; disposición final primera, apartado 1; disposición final tercera, apartado 3] que, como ya hemos anunciado, también ha sido objeto de un recurso de inconstitucionalidad contra los artículos 8 , apartado e), 10.1, 14.8, 15, 16, 17, disposición final tercera, apartado 3, y disposición final sexta de la citada Ley, que fue admitido a trámite por el Pleno del Tribunal en su providencia de 17 de octubre de 2017 y con la suspensión de su vigencia.

Ambas normas, la Ley 20/2014, que modifica el Código de consumo introduciendo la mediación obligatoria (art. 132-4.3) y la Ley 4/2016, que prevé este procedimiento en casos de sobreendeudamiento, constituyen un ejemplo de institucionalización

\footnotetext{
32 El párrafo tercero del preámbulo de esta Ley de modificación del Código de consumo catalán es clara: "La presente ley sigue las orientaciones marcadas por varios proyectos comunitarios sobre esta materia, como por ejemplo la Directiva 2014/17/UE del Parlamento Europeo y del Consejo, de 4 de febrero, sobre los contratos de crédito para los consumidores relativos a los bienes inmuebles de uso residencial".

${ }^{33}$ Esta mediación se desarrolla conforme al Decreto 98/2014, de 8 de julio, sobre el procedimiento de mediación en las relaciones de consumo. Dispone el art. 1: “Tiene por objeto la regulación del procedimiento de mediación previsto en el capítulo II del Título III, libro I, de la Ley 22/2010, del Código de Consumo de Catalunya, en el desarrollo de la previsión contenida a la disposición final segunda de la mencionada Ley". Según esta norma, la legitimación activa la tiene el prestatario consumidor con una vivienda habitual que pueda se afectado por un proceso de ejecución hipotecaria, de tal modo que si no insta esta mediación, la demanda relativa al proceso de ejecución hipotecaria no podrá ser admitida a trámite (v. Pérez Daudí 2015, p. 4).

${ }^{34}$ Con esta disposición final quinta se añade un apartado, el 4, al artículo 132-4 de la Ley 22/2010, de 20 de julio, del Código de consumo de Cataluña, por el cual se dispone que "en situaciones de sobreendeudamiento derivado de relaciones de consumo, la mediación corresponde a las comisiones de sobreendeudamiento, reguladas por su legislación específica. Si las comisiones de sobreendeudamiento no alcanzan un acuerdo entre el consumidor y los acreedores, queda abierta la correspondiente vía judicial para hacer efectivo lo dispuesto por este código y la legislación complementaria."
} 
jurídica, ${ }^{35}$ en este caso, de este mecanismo extrajudicial, por razón del ámbito específico en el que este se desarrolla, que nació de entidades, principalmente, públicas y privadas para dar respuesta a una necesidad específica y concreta: favorecer la renegociación del préstamo o crédito hipotecario para evitar la pérdida de la vivienda a raíz del impago de la cuota.

De la primera regulación de la mediación de conflictos de consumo en materia de crédito o préstamo hipotecario en el Código de Consumo (art. 132-4.3) destacábamos la preceptividad de este procedimiento de mediación. De estas dos leyes, la 24/2015, y la 4/2016, ambas pendientes del recurso de inconstitucionalidad interpuesto contra determinados artículos de cada una de ellas, destacamos el particular procedimiento de mediación que se regula a cargo de las Comisiones, denominadas de Sobreendeudamiento en la Ley 24/2015 (art. 2.2.) y de Vivienda y Asistencia para Situaciones de Emergencia Social, conocidas con el acrónimo CHASES, ${ }^{36}$ en la Ley 4/2016 (art. 5 y ss).

Una Comisión de características similares se regulaba en la Ley francesa no 89-1010, de 31 de diciembre de 1989, sobre la prevención y resolución de las dificultades relacionadas con el sobreendeudamiento de personas y familias, derogada por el Código de Consumo francés, que la regula en el artículo L712-1 y siguientes de dicho cuerpo legal aunque, para alcanzar una solución consensuada entre el deudor y los acreedores, la legislación francesa menciona a la conciliación ("la commission s'efforce de concilier les parties en vue de l'élaboration d'un plan conventionnel de redressement approuvé par le débiteur et ses principaux créanciers", artículo L7321 Código de Consumo francés). ${ }^{37} 38$

Para una mejor comprensión, es conveniente decir que, en Cataluña, la CHASES tiene por objeto coordinar la actuación de las administraciones públicas de Cataluña en el establecimiento de mecanismos de solución de conflictos y la aplicación de las medidas de acción protectora establecidas por la presente ley, con la participación de entidades sin ánimo de lucro representativas de intereses afectados.

Dicha Comisión de Vivienda y Asistencia para Situaciones de Emergencia Social se estructura en secciones territoriales, cuya demarcación se corresponde con los ámbitos territoriales de las delegaciones del Gobierno. Depende del departamento competente en materia de vivienda. Pueden crearse secciones en otros ámbitos

\footnotetext{
35 Siguiendo la terminología empleada por Sabatier y Mazmanian en 1979, la implementación de los servicios de mediación hipotecaria en Cataluña responden a un proceso bottom-up, sabido es, de abajo hacia arriba, al ser una actividad de la red local, considerando de forma simultánea actores públicos (Ofideute, diputaciones provinciales y administración local en colaboración con los colegios de abogados) y privados (asociaciones para la defensa de consumidores y usuarios, entre otros), siendo posteriormente regulado (a partir de 2014, con la consabida modificación del Código de consumo, y en otras normas, como en el Decreto 75/2014, en cuyo artículo 72, se incorpora la labor del servicio de asesoramiento sobre la deuda hipotecaria conocido con la denominación de Ofideute tiene como finalidad dar apoyo y asesoramiento a las familias con problemas de pago de los préstamos hipotecarios de sus viviendas habituales y permanentes, con el fin de negociar una opción que permita evitar la exclusión residencial). Aunque también es cierto que la fuerte apuesta de la administración pública catalana, en particular, por la Agència de l'Habitatge de Catalunya, organismo de la Generalitat de Catalunya, en dar solución a este problema hipotecario, podría interpretarse que se trata de una implantación top-down. Esta implementación bottom-up suele tener mayor aceptación: “No debe confiar en ninguna institución para hacer cambios. Los cambios tienen que venir de abajo hacia arriba, de la gente en un nivel más micro. El papel adecuado de los tribunales parece ser más en hacer posible ese tipo de cambios, comprenderlos, darles la bienvenida, darles espacio, animarlos, pero no intentar institucionalizarlos" (Alfini et al. 1994, p. 332).

36 El acrónimo CHASES se corresponde con las iniciales de la denominación en catalán de la Comisión: Comissió d'Habitatge i Assistència per a Situacions d'Emergència Social.

37 Este articulo L732-1 Código de consumo francés fue redactado según lo dispuesto en la Ley no 20161691, de 9 de diciembre de 2016, relativa a la transparencia, a la lucha contra la corrupción y la modernización de la vida económica.

38 Otros países europeos también han adoptado medidas que tienen como objetivo favorecer un acuerdo entre deudor y acreedor. Es el caso de Alemania, donde la Ley reguladora de la insolvencia (Insolvenzordnung) fue modificada en 1999 para incorporar un procedimiento específico de insolvencia para consumidores. La sección 305 y siguientes de la Insolvenzordnung de 5 de octubre de 1994 ofrece las previsiones de los acuerdos extrajudiciales celebrados por el deudor y los acreedores.
} 
territoriales, mediante orden del consejero del departamento competente en materia de vivienda, en función del volumen de trabajo u otras necesidades técnicas, para mejorar su eficacia y eficiencia (art. 6 Ley 4/2016).

En los casos de consumidores que se encuentran en una situación de sobreendeudamiento derivada de una relación de consumo o que están en riesgo de encontrarse en dicha situación y excepto cuando existe un procedimiento judicial concursal (art. 10.2 Ley 4/2016), la mediación corresponde a estas comisiones de sobreendeudamiento (art. 132-4.4 CConsum), el procedimiento jurídico de la cual es de tal singularidad que nos plantea si estamos o no ante una mediación, de acuerdo con los principios que la definen.

\section{Los principios del proceso de mediación de conflictos de consumo en materia de crédito o préstamo hipotecario: sus particularidades}

La mediación en consumo en Cataluña, definida como un procedimiento que se caracteriza por la intervención de una tercera persona imparcial y experta, que tiene como objeto ayudar a las partes y facilitar la obtención por ellas mismas de un acuerdo satisfactorio (art. 132-1 CConsum), se rige por los principios de voluntariedad, imparcialidad, confidencialidad y universalidad (art. 132-2 CConsum). En el mismo sentido, el Decreto 98/2014, que aborda el procedimiento de mediación institucional de consumo que lleven a cabo las entidades acreditadas ${ }^{39}$ en el territorio de Cataluña. Se trata, por tanto, de los naturales ${ }^{40}$ principios reconocidos en los textos normativos internacionales.

Sin embargo, del análisis del artículo 132-4 de este mismo cuerpo legal, cuyos apartados 1, 2 y 3 fueron incorporados por la Ley 20/2014 que hemos estudiado anteriormente, y su apartado 4, incluido por la Ley 24/2015 y de la Ley 4/2016 que desarrolla el procedimiento de mediación en casos de sobreendeudamiento, entre ellos, por incumplimiento del deudor prestatario de la devolución del préstamo con garantía hipotecaria, se aprecian disposiciones que afectan, principalmente, a dos de los principios definitorios de este procedimiento extrajudicial como son la voluntariedad y la imparcialidad. Vamos a analizarlos a continuación.

\subsection{Principio de voluntariedad y mediación previa obligatoria en el Código de Consumo}

En Cataluña, la mediación en consumo del Decreto 98/2014 se concibe como un procedimiento voluntario (art. 2 Decreto 98/2014), al que las partes son libres de acogerse así como de desistir de él en cualquier momento (art. 132-2.2 CConsum; art. 5 Decreto 98/2014; art. 11 Ley 4/2016, que remite a los dos anteriores). ${ }^{41}$

\footnotetext{
${ }^{39}$ Las entidades acreditadas son, a efectos del Decreto 98/2014, los Servicios públicos de consumo, las organizaciones de personas consumidoras, las asociaciones y colegios profesionales, así como las otras entidades que reciban la acreditación con rango de ley. Esta consideración de las entidades contrasta con la concepción de la Directiva 2013/11/UE que expresamente dispone que las entidades de resolución alternativa de conflictos pueden ser tanto públicas como privadas, siempre y cuando estas últimas tengan financiación, recursos o web adecuadas (véase Vilalta 2014, p. 11).

40 El Decreto añade dos más: el principio de universalidad, según el cual la competencia de las entidades acreditadas se extiende a cualquier asunto que afecte a las personas consumidoras, con las excepciones establecidas en las leyes y el principio de territorialidad, por el que las entidades acreditadas deben ajustarse a lo previsto en el Decreto siempre que los hechos se hayan producido en territorio de Cataluña o cuando una de las partes tenga allí su domicilio, sin perjuicio de su aplicabilidad en el caso de conflictos transfronterizos.

${ }^{41}$ Haciendo uso de sus competencias en materia de defensa de consumidores y usuarios o en el área de vivienda, son varias las Administraciones de Comunidades que han desarrollado experiencias de mediación hipotecaria voluntaria: el Servicio de Orientación y Mediación Hipotecaria y de la Vivienda de la Comunidad Autónoma de la Región de Murcia (arts. 62-63 de la Ley murciana 6/2015, de 24 marzo, de la Vivienda); el Servicio de Mediación Hipotecaria de Navarra [art. 18.g) del Decreto Foral 128/2015, de 14 de agosto, sobre la estructura orgánica del Departamento de Derechos Sociales]; o el Programa de Mediación integral en materia de ejecuciones hipotecarias del Instituto de la Vivienda del Gobierno de La Rioja.
} 
Sin embargo, en los casos de ejecución hipotecaria de la vivienda habitual, el legislador catalán impone una mandatory mediation. Las partes en conflicto, antes de interponer cualquier reclamación administrativa o demanda judicial, deben acudir a la mediación o pueden acordar someterse al arbitraje (art. 132-4.3 CConsum). Aunque nos hallamos ante un proceso ejecutivo, que pretende el cumplimiento obligatorio y coercitivo que deriva de la existencia de un título ejecutivo, ello no impide que las partes traten de resolver la situación de impago de la deuda hipotecaria recurriendo a un medio autocompositivo como es la mediación (Quesada López 2017, p. 197) o hetercompositivo (arbitraje). ${ }^{42}$

Una vez transcurrido el plazo de tres meses a contar de la notificación del acuerdo de inicio de la mediación sin haber alcanzado un acuerdo satisfactorio, cualquiera de las partes puede acudir a la reclamación administrativa o a la demanda judicial. Estamos, pues, ante un ejemplo de "obligación de mediar" (Ginebra y Tarabal 2013, p. 5) que deriva inmediatamente de la ley.

Con este redactado, la mediación deviene, por tanto, un requisito de procedibilidad. La demanda de ejecución debe acompañarse de un documento acreditativo de que la mediación se ha intentado. ${ }^{43}$ De no ser así, la demanda judicial se inadmite.

No se trata de una cuestión baladí. La admisión de la obligatoriedad de acudir a mediación, reconocida en la normativa europea (Directiva 2013/11) ${ }^{44}$ ha sido refrendada, recientemente, por el Tribunal de Justicia de la Unión Europea, precisamente, en el caso de un conflicto por impago de una cantidad adeudada a una entidad financiera. Es la sentencia del Tribunal de Justicia de la Unión Europea (en adelante, TJUE) de 14 de junio de 2017.

En suma, la Unión Europea admite que el procedimiento de mediación sea preceptivo, ${ }^{45}$ que sea un requisito de admisibilidad de las demandas judiciales (en este sentido, v. Stroie 2017) en el ámbito de consumo puesto que no impide el acceso a la justicia, ${ }^{46}$ como así lo había manifestado el TJUE en otra resolución respecto de otra ADR, la conciliación en un conflicto de servicios de telecomunicaciones electrónicas (STJUE de 18 de marzo de 2010, punto 67). ${ }^{47}$

\footnotetext{
42 Considerando, por tanto, que la mediación puede tener cabida en un procedimiento de título ejecutivo, el hipotecario, también, se plantean no pocas cuestiones procesales que exceden el objeto de esta investigación y que se abordan con detalle en otros trabajos; véanse Sánchez Pos 2012, Ramos Méndez 2014, Quesada López 2017, 204 y ss.

${ }^{43}$ Y no se han alcanzado acuerdos, por lo que se recurre a la jurisdicción para ejecutar la finca.

${ }^{44}$ El artículo 1, segunda frase, de la Directiva 2013/11 establece explícitamente la posibilidad de que los Estados miembros establezcan la obligatoriedad de la participación en los procedimientos de resolución alternativa, siempre que su legislación no impida a las partes ejercer su derecho de acceso al sistema judicial. Ya anteriormente, la Directiva 2008/52/UE, en su Considerando 13, preveía que el Derecho nacional pueda dar a los órganos jurisdiccionales la posibilidad de poder señalar a las partes a acudir de la mediación, cuando resulte oportuno. Más adelante y ya en el texto de esta Directiva 2008/52, el artículo 2.1. c) prevé que sea obligatorio acudir a mediación según la legislación nacional de un estado miembro de la Unión Europea y, en esta misma línea, el artículo 3 a) establece la posibilidad de que este procedimiento pueda ser ordenado por un órgano jurisdiccional o prescrito por el Derecho de un Estado miembro. Aunque esta Directiva $2008 / 52$ no es de aplicación a la mediación en el ámbito del consumo, como se ha indicado anteriormente, porque tiene su propia regulación, las disposiciones que acabamos de citar ponen de manifiesto que la imposición de acudir a mediación no incide en la esencia de este procedimiento.

${ }^{45}$ Esta mediación preceptiva se ha impuesto en otros países, en Argentina, por ejemplo (Art. 2 de la Ley 13.151 de la provincia de Buenos Aires, 13/12/2010 y, en España, en otras jurisdicciones, como la laboral. Art. 63 de la Ley 36/2011, de 10 de octubre, reguladora de la jurisdicción social. Téngase presente también la inclusión de la conciliación, como medio voluntario para resolver algunos conflictos evitando el pleito, en la Ley 15/2015, de 2 de julio, de la Jurisdicción Voluntaria (arts. 139-148, Disposición Final 11 à.1 por la que se añaden los nuevos arts. 81, 82 y 83 a la Ley del Notariado y Disposición Final 12a que introduce un nuevo art. 103 bis en la LH).

46 Para Adán Domènech $(2015$, p. 4), la respuesta a tal cuestión debe ser rotunda, en el sentido de afirmar que no existiría vulneración alguna del derecho de acceso a los Tribunales.

47 En esta sentencia, el TJUE indica que el hecho de que una normativa nacional haya dispuesto la obligatoriedad del recurso a un procedimiento de ADR con carácter previo al ejercicio de una acción judicial no vulnera el derecho a la tutela judicial efectiva, siempre que -entre otros requisitos concernientes a la específica normativa enjuiciada - no conduzca necesariamente a una decisión vinculante para las partes,
} 
Esta mediación obligatoria, previa al proceso judicial, suscita alguna reticencia. ${ }^{48} \mathrm{El}$ principal argumento en contra de su establecimiento es que se corre el riesgo de que se convierta en una mera formalidad, cumplimentada de forma rutinaria, en un mero trámite previo pero sin una verdadera efectividad. ${ }^{49}$

Más aceptación tiene por la doctrina la asistencia obligatoria a una sesión informativa de mediación. En efecto, la voluntariedad no se contradice con la posibilidad de obligar a las partes a acudir a una sesión informativa, o con la fijación de medidas que induzcan a exigir la mediación como fase previa a una resolución impuesta por un tercero (juez o árbitro), siempre que no impidan el acceso a la tutela judicial, tal y como se presenta en la Ley 15/2009, de mediación en el ámbito de derecho privado de Cataluña (LMADP). ${ }^{50}$ La función de esta sesión informativa es asesorar "sobre el valor, las ventajas, los principios y las características de la mediación" (art. 11.1 LMADP, art. 5.1 Directiva 2008/52/CE). En consecuencia, obligar a las partes a asistir no vulnera el principio de voluntariedad - ya que ellas decidirán después de la sesión "si optan o no por la mediación" (art. 11.1 LMADP)-, ni les impide el acceso a la tutela judicial. ${ }^{51}$

La finalidad del legislador catalán al imponer esta mediación obligatoria, ${ }^{52}$ antes de presentar una demanda judicial de ejecución de la garantía que puede terminar en la adjudicación de la finca garantizada a un tercero, provocando que el propietario (el propio deudor pero también el fiador/avalista) pierda su vivienda, reside en favorecer y potenciar la adopción de medidas e instrumentos que permitan ayudar al deudor, en los términos del apartado segundo del art. 132-4 del Código de consumo: buscar acuerdos entre las partes que hagan viable que la persona consumidora conserve la propiedad de la vivienda ${ }^{53}$ o, subsidiariamente, asegurar la posibilidad de mantener su uso y disfrute (Adán Domènech 2015, p. 9).

Se trata, por tanto, de que las partes de esta relación de consumo, prestatario y prestamista, tengan a su disposición un espacio idóneo en el que puedan, en primer lugar, conocer la situación económica del prestatario y las posibilidades de modificación del contrato de préstamo o crédito con garantía hipotecaria del prestamista, ${ }^{54}$ para afrontar y valorar la posibilidad de restructurar, renegociar las condiciones del mismo, adaptándose a la situación económica, laboral y personal del deudor prestatario, gestionando amistosamente este conflicto en una materia tan sensible (Pérez Daudí 2015, p. 2).

no implique un retraso sustancial a la vía judicial, suspenda la prescripción de los correspondientes derechos, y no ocasione gastos, o estos sean poco significativos.

${ }^{48} \mathrm{Al}$ respecto, véase a favor de su inclusión como requisito preprocesal con carácter obligatorio, Bastante Granell 2013, p. 212. En contra, Cobas Cobiella 2014, pp. 29 y 30, Callejo y De Prada 2016, p. 617, Castillo Felipe 2016, p. 651. A favor de la propuesta de instaurar una fase prerrealizatoria en el proceso de ejecución hipotecaria, Quesada López 2017, p. 212.

${ }^{49}$ Ya en el año 2010, el Consejo General del Poder Judicial se pronunciaba en este sentido en su Informe al Anteproyecto de Ley de Mediación en Asuntos Civiles y Mercantiles, de transposición de la Directiva 2008/52, el cual preveía una mediación obligatoria previa en los procedimientos judiciales sobre reclamaciones de cantidad inferiores a 6.000 euros. Este órgano colegiado, integrado por jueces y otros juristas, que ejerce funciones de gobierno del Poder Judicial y que tiene la finalidad de garantizar la independencia de los jueces en el ejercicio de la función judicial frente a todos, argumentó en dicho Informe que si la finalidad del procedimiento de mediación es reducir la litigiosidad en los juzgados y tribunales, un trámite obligatorio lo único que conseguiría es "la agregación de nuevas cargas llamadas a lastrar el ejercicio del derecho de acceso a la justicia" como así sucedió con la conciliación previa.

50 Preámbulo de la LMADP: “[L]a voluntariedad del sistema para las partes no es un obstáculo para que esta ley establezca el derecho de éstas y la obligación consiguiente de asistir a una sesión informativa que acuerde el órgano jurisdiccional competente".

${ }^{51}$ Menos problemas presenta la sesión informativa obligatoria intrajudicial que tiene lugar como medida complementaria y bajo el control judicial (v. Merelles Pérez 2016, p. 4).

${ }^{52}$ Acerca de la mediación obligatoria en materia de consumo, véase también Orozco Pardo 2016, p. 683.

${ }^{53}$ Sugieren la mediación extrajudicial obligatoria como una medida útil Collins y Urban (2015) y Renuart (2012, p. 581).

${ }^{54}$ En su estudio, Collins y Urban (2015) destacan, precisamente, que la mediación permite conocer los motivos por los cuales el prestatario no hizo frente al pago de su deuda. 
El carácter voluntario de la mediación reside no tanto en la libertad de las partes de recurrir o no a este procedimiento sino en la autonomía de la voluntad de cada una de ellas en decidir libremente si quieren o no alcanzar acuerdos de solución, por consiguiente, si quieren iniciar este procedimiento extrajudicial, cómo organizarlo y desistir de él en cualquier momento. Se les podría obligar a acudir a mediación, ${ }^{55}$ pero no se le puede obligar a alcanzar acuerdos de solución.

3.2. Imparcialidad y neutralidad y la actuación del mediador en las Leyes para protección del derecho a la vivienda de las personas en riesgo de exclusión residencial

La imparcialidad y la neutralidad suelen ser, junto con la voluntariedad y la confidencialidad, otros de los caracteres naturales del procedimiento de mediación instituidos en los ordenamientos jurídicos internacionales (Vilalta 2010, p. 129) y nacionales. ${ }^{56}$

Estos dos principios definitorios de la mediación suelen ir de la mano, puesto que ambos se predican de la actividad o actitud de la persona mediadora durante el proceso. ${ }^{57}$ De hecho, en el ámbito del derecho privado, el legislador catalán los enuncia conjuntamente (art. 6 LMADP), lo que no pocas veces comporta confusión o indefinición.

Una primera nota diferenciadora la situamos en el propio procedimiento. El principio de imparcialidad es aplicable al desarrollo del proceso de mediación y comporta que el mediador debe tratar a las partes del mismo modo por igual, sin favoritismos, ni prejuicios personales respecto de alguna de ellas, por razón de sus características, orígenes, valores, creencias o cualquier otra razón, e implica asimismo no aceptar favores o regalías. ${ }^{58}$ El segundo, el principio de neutralidad, se refiere al resultado de dicho proceso ${ }^{59}$ y consiste en que el mediador no puede proponer formalmente (Vilalta 2010, p. 158) ni imponer soluciones.

La imparcialidad del mediador significa que, en su intervención, no ha de apoyar el interés o los puntos de vista de ninguna de las partes en conflicto, ni actuar en perjuicio de sus posiciones. Es habitual su enunciación legal como un deber de la persona mediadora, cuyo incumplimiento es un hecho constitutivo de infracción (art. 30. a de la LMADP) y, como tal, objeto de sanción (art. 32 LMADP). Dado el carácter autocompositivo del procedimiento de mediación y el principio de voluntariedad que legitima a las partes a desistir en cualquier momento (arts. 5, 15.1 LMADP), es aconsejable que la persona mediadora, además de respetar el principio de imparcialidad en su actuación, procure que dicho respeto sea así percibido por las

\footnotetext{
55 La Directiva 2008/52, de 21 de mayo, sobre ciertos aspectos de la mediación en asuntos civiles y mercantiles, en su artículo 3, a), primer párrafo, in fine, admite esta posibilidad: “Este procedimiento puede ser iniciado por las partes, sugerido $u$ ordenado por un órgano jurisdiccional o prescrito por el Derecho de un Estado miembro".

56 De la lectura de los preceptos de la Ley estatal 5/2012 y de la legislación autonómica sobre mediación, en general, aunque principalmente en el ámbito familiar se observa que la imparcialidad y la neutralidad aparecen en todas las legislaciones analizadas. Así, por ejemplo, en los artículos 7 (imparcialidad e igualdad de partes) y 8 (neutralidad) de la Ley 5/2012. Véase un cuadro sobre los principios en cada legislación en Esteve García 2011, p. 52.

57 En la Ley catalana 15/2009, se sitúan en la misma definición de su artículo 1 LMADP: "persona mediadora que actúa de una manera imparcial y neutral". También aparecen entre los principios definitorios, en el preámbulo, apartado IV, de la Ley 5/2012.

58 La Comisión Europea para la Eficacia de la Justicia (European Commission for the Efficiency of JusticeCEPEJ) del Consejo de Europa, en su informe de 2014, distingue, precisamente, la mediación y la conciliación en el hecho de que, frente al mediador, el conciliador "can suggest to the parties proposals for the settlement of a dispute. Compared to a mediator, a conciliator has more power and is more proactive" (CEPEJ 2014). También la doctrina se ha pronunciado en este sentido. Por ejemplo, Vilalta 2010, p. 158, Marqués Cébola 2013, p. 92.

59 Esta diferenciación entre imparcialidad y neutralidad se encuentra en la Recomendación R (98) 1 del Consejo de Ministros a los Estados miembros sobre la mediación familiar, de 21 de enero de 1998. Según el Consejo, el mediador es imparcial en sus relaciones con las partes y neutral con respecto al resultado del proceso de mediación.
} 
partes, como recomienda el art. 2.2 del Código de Conducta Europeo para Mediadores (el mediador, además de actuar imparcialmente con las partes en todo momento, "se esforzará en demostrar su imparcialidad"; Lauroba et al. 2010, p. 841).

Por su parte, en la neutralidad, partimos de la función de la mediación: que las partes se avengan a buscar por ellas mismas la solución del conflicto (art. 1 LMADP). De ahí que la actividad de la persona mediadora es, en principio, de mera asistencia y facilitación, sin en ningún caso revestir naturaleza decisoria. En otras palabras, la persona mediadora no puede "imponer ninguna solución ni ninguna medida concreta" (art. 6.2 LMADP). La no imposición de la solución es la esencia de la neutralidad ${ }^{60}$ y el índice que diferencia la mediación de los métodos heterocompositivos de resolución de conflictos, como el procedimiento judicial y el arbitraje.

En el ámbito de la mediación de consumo en Cataluña, es el Decreto 98/2014 el que informa de la tarea que tiene encomendada el mediador: facilitar el diálogo, promover la comprensión entre las partes y ayudar a buscar soluciones al conflicto; velar porque las partes tomen sus propias decisiones, tengan la información y asesoramiento suficientes para llegar a alcanzar acuerdos de una manera libre y consciente; informar adecuadamente sobre las vías alternativas de resolución del conflicto en caso de finalización del procedimiento de mediación sin que se haya llegado a un acuerdo (art. 11 Decreto 98/2014). ${ }^{61}$

Estos principios, en particular, el de neutralidad y estos deberes ("ayudar a buscar soluciones"; "velar porque las partes tomen sus propias decisiones") contrastan de forma clara con la práctica que llevan a cabo las entidades públicas y privadas que desarrollan el procedimiento de mediación en los conflictos de impago de los préstamos y créditos hipotecarios.

Sirva como ejemplo el servicio Ofideute de la Agencia de la Vivienda de Cataluña, que ofrece a las familias un canal de comunicación con la entidad financiera para renegociar las condiciones de los préstamos (http://agenciahabitatge. gencat.cat/wps/portal/serveis/ofideute y https://web.gencat.cat/es/tramits/tramits-temes/Ofideute-Servei- dassessoramentsobre-el-deute-hipotecari?evolutiuTramit $=1$ ). Se presenta como un servicio gratuito de información y asesoramiento, que analiza el caso, que elabora una propuesta de solución al conflicto derivado del impago de la cuota, que actúa como interlocutora con la entidad financiera, entregándole dicha propuesta para su valoración y que realiza un seguimiento de la respuesta y las posibles contraofertas. Ofideute finaliza su actuación cuando obtiene la resolución definitiva de la entidad. La propuesta de Ofideute no tiene carácter preceptivo ni vinculante. Las entidades financieras no quedan obligadas y podrían decidir iniciar la vía judicial o notarial para la reclamación de la deuda, si fuera el caso, como prevé la ley (Ruiz de la Fuente 2014).

La justificación de esta intervención más activa de la entidad pública se suele fundamentar en el desequilibrio de poder existente entre las dos partes, entre el propietario consumidor y la entidad financiera. El propietario que tiene su vivienda hipotecada en garantía del pago de un préstamo o crédito que se concertó para adquirir esta misma vivienda u otra ${ }^{62}$ puede carecer de los conocimientos financieros o técnico-jurídicos necesarios ${ }^{63}$ para alcanzar un acuerdo de solución que consiste en una renegociación de las condiciones del préstamo inicialmente contratado. Por todo

\footnotetext{
${ }^{60}$ Que el mediador debe ser neutral, incluso, en la mediación hipotecaria es una postura defendida por algunos autores norteamericanos. Véase, por todos, Hagerott 2012, p. 917.

${ }^{61}$ Estos deberes del mediador se concretan en la actividad que debe desarrollar como convocar a la partes cuando proceda, velar para que tenga asesoramiento suficiente para alcanzar los acuerdos de una manera libre y consciente, adoptar las medidas para la gestión del procedimiento y finalizar el procedimiento de mediación, justificadamente, si considera que no se puede resolver el conflicto mediante esta vía (art. 12 Decreto 98/2014).

62 Sería el caso del progenitor que hipoteca su propia vivienda en garantía del préstamo que su descendiente ha concertado.

${ }^{63}$ Sobre el desequilibrio de información entre las dos partes del préstamo, véase Vázquez de Castro 2013, p. 3998.
} 
ello, los encargados de estos servicios desarrollan dos labores: de un lado, una labor de asesoramiento u orientación y/o, de otro, una labor de representación del usuario a la hora de realizar la encomienda de negociaciones en nombre de aquél con la entidad bancaria. El interlocutor propone una opción de solución que, en nombre del usuario del servicio, presenta a la entidad financiera. ${ }^{64}$

En esta misma línea, en los casos de sobreendeudamiento y para evitar los supuestos de exclusión residencial, la legislación catalana prevé el deber del mediador designado de elaborar un estudio de orientación con el análisis del activo actual y futuro previsible y el pasivo actual y futuro del deudor, su situación personal y familiar $y$, si procede, los planes convencionales de reestructuración de las deudas, aportados por los distintos acreedores, y debe proponer un plan de saneamiento para superar la situación económica del deudor (art. 13 Ley 4/2016). ${ }^{65}$

En relación con esta labor activa de las entidades públicas y/o privadas en el ámbito del préstamo o crédito hipotecario, se ha cuestionado si es o no mediación, ya que reciben denominaciones distintas, que aparecen con frecuencia entremezcladas (Gutiérrez Santiago 2015, p. 38) tanto en la normativa legal como también en las webs de los servicios de las Administraciones autonómicas y municipales o de los Colegios de abogados, anteriormente citadas.

Seguidamente, pasamos a analizar las interpretaciones de la doctrina acerca de la actuación del mediador en estos conflictos sobre préstamos hipotecarios entre consumidor y entidad financiera.

\subsubsection{No es mediación: es intermediación}

Un sector doctrinal entiende que la gestión del conflicto hipotecario realizado por estas entidades públicas o privadas que no constituye una mediación puesto que, en cierto modo, se considera que estas entidades actúan en nombre y en defensa de los intereses del deudor, o lo que es lo mismo, intervienen de un modo parcial, por tanto, de modo contrario a uno de los principios rectores de este procedimiento como es la imparcialidad.

La justificación de esta intervención se asienta en la consideración de que, en la mayoría de los casos, se entienda que existe un desequilibrio de poder, con una parte más débil, el consumidor, que debe ser potenciada y cuya posición en la negociación debe ser reforzada por este tercero, que impide que exista una imparcialidad estricta. Como hemos expuesto, generalmente, las personas mediadoras actúan ante este conflicto hipotecario, amparadas por una institución mediadora de la que forman parte y que les apoya en sus gestiones con la entidad financiera. Este apoyo compensa, en parte, el desequilibrio de poder entre prestatario y prestamista, porque la persona mediadora se presenta avalada por una institución de prestigio que le da una cierta fuerza en el momento de presentar y apoyar las propuestas formuladas. Es más, estas instituciones mediadoras pueden haber establecido, previamente, contactos o acuerdos, escritos o no, con distintas entidades crediticias. Estos convenios dan cobertura a las gestiones, contactos y negociaciones que realizan los mediadores con los Bancos y facilitan un canal de comunicación directa que puede resultar de suma utilidad en la renegociación del préstamo o crédito hipotecario (Vall Rius 2012, apdo. II, punto 3, p. 14).

\footnotetext{
${ }^{64}$ En esta misma línea trabaja el Servicio del País Vasco. El mediador es, aquí, “un profesional del ámbito económico, miembro del Turno de Actuación Profesional (T.A.P.), que se encargará de estudiar tu capacidad económica, hablar con la entidad financiera y ofrecerte atención social".

${ }^{65}$ En una línea de actuación similar a la del mediador concursal. Art. 236 de la Ley 22/2003. Sin embargo, la propia Ley 4/2016 excluye de su ámbito de actuación los conflictos en que se ha iniciado el procedimiento de concurso.
} 
Al no cumplirse la imparcialidad, uno de los principios rectores de la mediación, ${ }^{66}$ los autores entienden que la intervención de este mediador no puede calificarse como mediación y la denominan "intermediación" hipotecaria. ${ }^{67}$

El desequilibrio de poder puede provenir de la falta de información del consumidor respecto de sus derechos y de las opciones económicas que se dispone para solucionar su conflicto, en el caso del préstamo hipotecario, la medida o medidas óptimas para la renegociación de la deuda en atención a sus concretas circunstancias financieras, laborales y personales o familiares. Si ello es así, cuando el consumidor dispone de esta información y la utiliza en la negociación con la entidad financiera, el consumidor podría reequilibrar su posición ${ }^{68}$ en la negociación, no olvidemos, en una relación contractual de préstamo o crédito, por tanto, de obligado cumplimiento. ${ }^{69}$ En caso de que no tenga esa información, habrá que propiciar que disponga de ella. ${ }^{70}$

\subsubsection{Es una mediación calificada como "evaluativa" o "directiva"}

Otra de las interpretaciones es la que considera que nos encontramos ante un procedimiento de mediación, en su modalidad evaluativa o directiva.

Tradicionalmente, se ha considerado que la labor del mediador en el ámbito civil, particularmente, el familiar, consiste en facilitar a las partes en un conflicto de un espacio en el que comunicarse para gestionar dicha situación, sin proponer opciones de solución. El mediador facilitador asume que las partes son capaces de trabajar con sus contrapartes, y capaces de entender sus situaciones mejor que el mediador. El mediador facilitativo no da su opinión, ya que con ello interferiría en su imparcialidad y, también, porque el mediador puede no conocer de manera suficiente los detalles del caso, las cuestiones legales o tecnológicas del caso como para dar una opinión informada. En consecuencia, las partes pueden generar por sí mismas mejores soluciones que cualquier mediador podría crear (Riskin 2009, p. 111). La mediación facilitadora se centra principalmente en los intereses de las partes: un mediador facilitador busca aumentar la comprensión entre las partes, explora sus intereses en lugar de promover una posición, crea un ambiente colaborativo y ayuda a las partes a crear una solución, que es única en su situación. En una mediación facilitadora típica, el mediador hace preguntas para entender la situación y sutilmente dirige a las partes a explorar opciones y resultados potenciales. Bajo este enfoque facilitativo, las partes esperan que el mediador interfiera lo menos posible con la discusión de las partes, centrándose en facilitar y guiar la discusión para que las negociaciones no se rompen (Roberts 2007, p. 193).

\footnotetext{
${ }^{66}$ Acerca del desequilibrio de poder de las partes, véase por todos Vall Rius 2012, pp. 8 y 9.

67 Ofideute ofrece asesoramiento, mediación e intermediación hipotecaria. También muchos municipios cuentan con este servicio de intermediación en sus oficinas de vivienda en toda Cataluña; también canalizado a través de la Diputación provincial como el Servicio de Intermediación en la Deuda Hipotecaria (https://www.diba.cat/es/web/benestar/sidh). Con posterioridad también encontramos estos servicios en otras comunidades, por ejemplo, la Oficina de Intermediación Hipotecaria del Principado de Asturias. O también los abogados, a través del Servicio de Intermediación Hipotecaria. En el País Vasco, se sigue denominando "mediación hipotecaria" (http://www.justizia.net/biblioteca/servicio-de-mediacionhipotecaria).

${ }_{68}^{6}$ Nos preguntamos si este asesoramiento que se realiza para esta reestructuración del crédito o préstamo al que no pude hacerse frente no podría haberse llevado a cabo antes de concertarlo. Una de las mayores inversiones económicas que una persona lleva a cabo a lo largo de su vida, como es la adquisición de una vivienda, se realiza la mayor parte de los casos sin la intervención de un profesional que asesore y oriente al consumidor sobre las cláusulas legales y económicas del contrato y de la garantía hipotecaria.

${ }^{69}$ Las diferencias entre la intermediación hipotecaria y la mediación se detallan en Callejo y De Prada 2016, p. 616, y Quesada López 2017, pp. 198-202.

70 Sobre el desequilibrio de información: "One implication of this finding is that information asymmetry is at least one cause of friction in the mortgage market that could be dragging down loan modification rates. Given the revealed preference at the federal level and among the mortgage industry for loan modifications over other options (such as special bankruptcy provisions, loan forgiveness, public refinancing programs, direct borrower subsidies or income support), the fact that information problems are partially responsible might suggest a need for greater attention to third-party out-of-court mediators in judicial states and preforeclosure counseling in trustee foreclosure jurisdictions." (Collins y Urban 2015, p. 1737)
} 
Para que el proceso facilitativo funcione, la doctrina entiende que el mediador no necesita experiencia en el objeto de la controversia. Su propósito es sólo hacer preguntas en vez de sugerir soluciones, juzgar, o de otra manera brindar consejo. Por lo tanto, es raro que un mediador facilitador tenga experiencia en la materia. En la mayoría de los casos, en la mediación facilitadora se prefiere que el tercero mediador no tenga experiencia en el área en disputa. Con ello, la falta de experiencia elimina el peligro de que el mediador le proporcione información evaluativa. En cambio, un mediador facilitador sólo necesita saber cómo facilitar las negociaciones entre las partes, o tener procesos experiencia. Cuando sea necesaria información adicional, el procedimiento requiere que el mediador recomiende que las partes reciban el asesoramiento profesional o jurídico.

El mediador facilitativo permite a las partes expresar sus puntos de vista, les ofrece la oportunidad de ser escuchados. En este enfoque orientado al futuro, las principales tareas del mediador facilitador son 4: ayudar a las partes a entender los intereses subyacentes, ayudar a las partes en el desarrollo y el intercambio de sugerencias de arreglo de intereses basadas en intereses, ayudar a las partes a intercambiar propuestas y ayudar a las partes evaluar esas propuestas (Riskin 1996, pp. 32-34).

Frente a este modelo facilitativo, la actuación del mediador en consumo prevista en las leyes 24/2015 y 4/2016 podría ser encuadrada dentro del marco de la denominada mediación evaluativa. En general, el mediador que evalúa asume que las partes quieren y necesitan que les provea algún tipo de guía de los fundamentos para un acuerdo, asentados en la ley, la práctica industrial o la tecnología para lo cual el mediador está cualificado para proporcionarla en virtud de su entrenamiento, experiencia y objetividad (Riskin 1994, p. 111).

El mediador evaluativo, al analizar y formular propuestas, elimina parte de la carga de la toma de decisiones de las partes. En algunos casos, esto facilita que las partes lleguen a un acuerdo. Las evaluaciones del mediador pueden dar a un participante una mejor comprensión de su mejor alternativa a un acuerdo negociado (MAAN). ${ }^{71}$ Esta intervención propositiva del mediador, en opinión de Riskin (1996), puede interferir, no obstante, con la comprensión de las partes de sus propias posiciones y de los intereses de cada uno y, por lo tanto, hacer que el proceso sea más contradictorio.

Con esta modalidad evaluativa, se evitarían ciertos riesgos de la modalidad facilitativa. Cuando los partes del conflicto no son suficientemente conocedores de la materia o hábiles para desarrollar propuestas o negociar unos con otros, pueden no reconocer cuestiones o intereses relevantes, desarrollar plenamente opciones, 0 llegar a un acuerdo que sea bueno - por lo que sean las normas- como lo harían con un mediador más evaluativo. Además, un enfoque de facilitación mal conducido podría perder mucho tiempo si no responde a intereses subyacentes ni en el proceso ni en el resultado (Riskin 1996, p. 46).

El mediador aporta una orientación técnica que supone un elemento relevante para avanzar hacia el acuerdo, interpretación que es objeto de crítica (Love 1997) por algunos autores, pues se entiende que lo que se persigue es una solución rápida en un juego de concesiones (Iturmendi y Rodríguez 2017, p. 3). Precisamente por ello, la doctrina ha destacado la importancia de conocer la materia objeto de conflicto en áreas con un alto nivel de especificidad como es en el marco de las patentes, antitrust, cuestiones tributarias y, tal vez, insolvencia (Arnold 1995, p. 69).

De ahí que podría interpretarse que el proceso que se lleva a cabo en este contexto conflictivo (el hipotecario), la proposición del denominado mediador en estas organizaciones públicas y privadas se encamina a ofrecer a ambas partes una o varias opciones de solución que permitan satisfacer sus respectivos intereses. En todo caso,

\footnotetext{
${ }^{71}$ En inglés, BATNA - Best Alternative to Negotiated Agreement (Riskin. 1996, p. 44).
} 
no se trata de una imposición de este tercero, sino una proposición sujeta a la voluntad de las partes de aceptarla o no.

La actuación del mediador será más o menos facilitativa en función de si el consumidor tiene o no la información y los conocimientos necesarios para tomar una decisión sobre las opciones de que dispone para evitar quedarse sin su vivienda en las sesiones con la entidad financiera. Si no dispone de ella, será un tercero quien realice la propuesta de solución, que podrá ser valorada por la entidad financiera. Caso de admitir esta modalidad de mediación evaluativa, cabría pensar en la necesidad de establecer unos estándares distintos del modelo facilitativo. ${ }^{72}$

\subsection{3. ¿Es un evaluador neutral?}

Otra de las posturas que tratan de dar respuesta a esta particular actuación del mediador en este ámbito es la que considera que se trata más de un evaluador neutral. Como se recordará, la evaluación neutral es un proceso mediante el que un tercero, experto e independiente de las partes (evaluador), emite un informe respecto a las posiciones y argumentos de hecho y/o derecho de cada parte, así como un sumario de recomendaciones sobre las que las partes pueden construir su propio acuerdo y resolver sus desavenencias.

Desde su imparcialidad y experiencia profesional, el evaluador que las partes elijen libremente ayuda a cada una de ellas a valorar sus respectivas posturas y argumentos. Además, el evaluador plantea en su informe recomendaciones independientes sobre las que las partes pueden construir un acuerdo que satisfaga a ambas (Quesada López 2017, p. 202).

El evaluador elabora una valoración confidencial de las perspectivas de un caso, las asiste en la elaboración de un plan, evalúa los costes y explora la viabilidad de una sesión de seguimiento para lograr la solución exitosa de un caso (United Nations Conference on Trade and Development-UNCTAD 2010, p. XVII).

El evaluador neutral hace sugerencias a las partes sobre cómo debe resolverse la disputa. Aunque estas son libres de rechazar estas recomendaciones, la posición y la influencia del neutral pueden ser muy persuasivas (World Bank Group 2011, p. 9). Aunque la opinión no es vinculante, proporciona una evaluación imparcial de las posiciones y orientaciones relativas en cuanto al resultado probable si el caso fuera escuchado en los tribunales.

Este procedimiento no termina con una solución impuesta por el evaluador, sino en el posterior acuerdo que éstas puedan alcanzar como resultado de su análisis y recomendaciones.

En resumen, encontramos autores que le otorgan "autonomía propia" y la configuran como una "mediación sui generis", como una tipología propia de ADR (Cobas Cobiella 2014 , p. 19, Blanco García 2015b, pp. 14-15, 17-19), mientras que otros autores le niegan tal entidad autónoma y consideran que se trata de "una especialidad de la mediación de consumo, puesto que centra su actividad en una determinada clase de consumidores: los deudores hipotecarios; en un ámbito concreto de su protección: la reestructuración del préstamo hipotecario y la evitación de la ejecución; y en la defensa de un específico bien de uso o consumo común, ordinario y generalizado de protección prioritaria: la vivienda" (Bastante Granell 2013, pp. 190-191) o hasta se concibe como una figura híbrida entre la negociación asistida y la mediación (Cobas Cobiella 2014, p. 20).

En función de cual sea la calificación que se realice de la actuación de esta tercera persona que trata de proporcionar un mecanismo de gestión de los conflictos en

\footnotetext{
72 De hecho, podrían incluso considerar formar una organización profesional separada que les permita trabajar de manera más eficaz para promover el uso de procesos no evaluativos (v. Baruch Bush 2002, p. 130).
} 
materia de préstamos hipotecarios, los principios por los que se rige ${ }^{73}$ y los deberes que le son exigidos pueden ser muy dispares hasta tal punto que nos cuestionamos cuál es el denominado "core standards of mediation" (Shapira 2016, p. 88).

Desde un punto de vista social, bienvenidos todos estos servicios y mecanismos encaminados a impedir a los ciudadanos la pérdida de la vivienda en situaciones de sobreendeudamiento sobrevenido mediante el ofrecimiento de un proceso que permite acuerdos que puedan satisfacer los intereses de todas las partes implicadas.

\section{Consideraciones finales}

La institucionalización de la mediación en la gestión de los conflictos derivados del impago de las cuotas de los préstamos y créditos con garantía hipotecaria en Cataluña se puede calificar de singular. Dentro del marco de la Unión Europea, el derecho de consumo, en general, y las ADR han sido objeto de una regulación exhaustiva con la finalidad de proporcionar al consumidor y usuario de una protección $y$, a su vez, de unos procedimientos que sean eficaces para la defensa de estos derechos. Y de ahí el impulso de los mecanismos alternativos de resolución de litigios. Esta regulación ha seguido un proceso de institucionalización top-down: de la Unión europea a los Estados miembros y sus ciudadanos.

Pese a este impulso normativo de las ADR en consumo en general, la mediación como procedimiento de gestión de los conflictos de consumo en materia de préstamos y créditos hipotecarios se ha iniciado con las actuaciones de los servicios públicos y privado de mediación, que han tratado de paliar una situación dramática cual es la eventual pérdida de la vivienda habitual de un consumidor que ha adquirido un inmueble como residencia habitual a raíz consecuencia de un sobreendeudamiento sobrevenido. A partir de esta actuación de las entidades, públicas y privadas, y también las corporaciones de derecho público, como los colegios profesionales, el legislador catalán ha querido extenderla y, por ello, ha regulado, en primer lugar, una mediación preceptiva previa a la interposición de la demanda de ejecución de la vivienda por impago de la cuota del préstamo o crédito hipotecario que esta garantiza; en segundo lugar, un procedimiento de mediación sui generis con una intervención propositiva del mediador que puede ser modificada y modalizada por una Comisión de Sobreendeudamiento o la CHASES previstas en la Ley 24/2015 y la $4 / 2016$, respectivamente. ${ }^{74}$ Se trata, por tanto, de una institucionalización bottomup (de abajo hacia arriba).

La regulación de la mediación en un ámbito tan concreto de la relación de consumo como lo es el de los conflictos por impago de los préstamos y créditos hipotecarios supone una potencialidad en el fomento de este procedimiento. La mediación sigue siendo, a día de hoy, todavía, poco conocida y solo se podrá recurrir a ella si se promociona y los ciudadanos la contemplan como una opción a tener en cuenta en el momento de gestionar esta (y otra) situación conflictiva. Cierto es, también, que la mediación es, en el Sistema arbitral de consumo, una fase, voluntaria, dentro de un proceso, el arbitraje, también voluntario; justamente, un Sistema al que poco recurren las entidades financieras para gestionar estos conflictos. Un procedimiento regulado pero infrautilizado.

Por otra parte, del análisis específico de las fases del procedimiento de resolución de este conflicto que estas dos leyes mencionadas prevén se puede plantear la cuestión de si estamos o no ante una mediación pues dos de los principios, tradicionalmente considerados los pilares que la sustentan, se tensionan hasta el punto de hacer temblar a la institución. El requisitos de procedibilidad previo a la interposición de la demanda de ejecución hipotecaria por una parte y la posibilidad de que el mediador

\footnotetext{
${ }^{73}$ Algunos autores consideran que la mediación hipotecaria no difiere del procedimiento que se desarrolla en otra tipología de conflictos. En este sentido, véase Hagerott 2012, p. 908.

74 En el momento de cerrar este trabajo, ambas leyes están pendientes de sendos recursos de inconstitucionalidad interpuestos contra algunos de sus artículos.
} 
realice propuestas de solución a las partes cuestiona hasta qué punto la voluntariedad y la imparcialidad y neutralidad de la persona mediadora constituyen dos fundamentos esenciales en este procedimiento concreto.

La variedad de formas de actuación de este tercero puede tener cabida bajo este concepto flexible que caracteriza la mediación porque el procedimiento en sí mismo lo es. Se adapta adecuadamente al tema de la controversia, sus hechos y circunstancias y a los intereses de las partes. Es necesario, pues, un análisis exhaustivo de cuál es la esencia de la actuación de esta tercera persona que gestiona un espacio de comunicación y diálogo entre las partes en conflicto, para identificarla con claridad, para diferenciarla de otros mecanismos, para establecer cuáles son los estándares de la lex artis y la ética del mediador y, en definitiva, favorecer que la mediación desarrolle toda su potencialidad sin que con ello se olvide ni deje de lado una práctica mediadora que se acomoda a cada ámbito objetivo y subjetivo de la controversia.

\section{Referencias}

Adán Domènech, F., 2015. ¿Instauración de una ejecución hipotecaria especial en Cataluña? Diario La Ley, no 8631, pp. 1-19.

ADICAE, s.f. El acceso a la justicia de los usuarios de servicios financieros [en línea]. Disponible en:

http://asp.adicae.net/proyectos/internacionales/permanentforum/download/di cta/dicta1les.asp [Con acceso el 4 de julio de 2018].

Alfini, J. et al., 1994. What happens when mediation is institutionalized? To the parties, practitioners, and host institutions. Ohio State Journal on Dispute Resolution, no 9, pp. 307-332.

Anderson, M., 2016. La Directiva 2014/17/UE, sobre créditos hipotecarios, y su previsible impacto en el derecho español. En: E. Arroyo Amayuelas y A. Serrano de Nicolás, eds. La europeización del derecho privado: cuestiones actuales. Cátedra J ean Monnet de Derecho Privado Europeo de la Universidad de Barcelona, Colegio Notarial de Cataluña. Madrid: Marcial Pons, pp. 45-64.

Arnold, T., 1995. 20 common errors in mediation advocacy, Alternatives to the high cost of litigation. CPR Institute for Dispute Resolution, 13(5), p. 69.

Barral Viñals, I., 2012. El cliente y el consumidor de servicios financieros de crédito hipotecario. En: E. Lauroba Lacasa, dir., y J. Tarabal Bosch, eds., Garantías reales en escenarios de crisis: presente y prospectiva [en línea]. Barcelona: Marcial Pons, p. 473 y ss. Disponible en:

https://www. marcialpons.es/media/pdf/9788497689922.pdf [Con acceso el 4 de julio de 2018].

Barral Viñals, I., 2014. Consumidores, Online Dispute Resolution y reclamaciones de pequeña cuantía. Democracia Digital e Governo Eletrônico, 1(10), p. 404.

Barral Viñals, I., 2015. Si no queda satisfecho... ¡reclame!: el futuro de la resolución de conflictos de consumo [en línea]. 19 de mayo. Universidad de Castilla-La Mancha: Centro de Estudios de Consumo. Disponible en: http://blog. uclm. es/cesco/files/2015/05/CESCO-anteproyecto-conflictos-deconsumo-Inma-Barral.pdf[Con acceso el 4 de julio de 2018].

Barral, I. y Suquet, J., 2010. La mediación en el ámbito de consumo. En: P. Casanovas, J. Magre y M.E. Lauroba, dirs., El libro blanco de la mediación en Cataluña [en línea]. Barcelona: Generalitat de Catalunya / Huygens, p. 305 y ss. Disponible en: http://idt-magui.uab.cat/downloads/LibroBlanco.pdf [Con acceso el 4 de julio de 2018].

Baruch Bush, R.A., 2002. Substituting Mediation for Arbitration: The Growing Market for Evaluative Mediation, and What It Means for the ADR Field. 
Pepperdine Dispute Resolution Law J ournal [en línea], 3(1). Disponible en: https://digitalcommons.pepperdine.edu/drlj/vol3/iss1/6 [Con acceso el 4 de julio de 2018].

Bastante Granell, V., 2013. Mediación hipotecaria: una solución al problema del sobreendeudamiento de los particulares. Anales de Derecho [en línea], no 31. Disponible en: http://dx.doi.org/10.6018/analesderecho [Con acceso el 4 de julio de 2018].

Bel i Queralt, G., y Estruch Manjón, A., 2009. Crisis financiera y regulación. Tentación, pecado, penitencia y propósito de la enmienda. El Cronista, no 4, pp. 50- 57.

Berrocal Lanzarot, A.I., 2012. La vivienda hipotecada en la actual situación de crisis económica En: E. Lauroba Lacasa, dir., y J. Tarabal Bosch, coord., Garantías reales en escenarios de crisis: presente y prospectiva [en línea]. Barcelona: Marcial Pons, pp. 493-494. Disponible en: https://www. marcialpons.es/media/pdf/9788497689922.pdf [Con acceso el 4 de julio de 2018].

Blanco Carrasco, M., 2009. La alternativa de la mediación en conflictos de consumo: presente y futuro. Anuario Jurídico y Económico Escurialense, XLII, pp. 129-152.

Blanco García, A.I., 2015a. El Anteproyecto de Ley de Resolución Alternativa de Conflictos de Consumo y su encaje en el sector financiero. Revista CESCO de Derecho de Consumo, n 15.

Blanco García, A.I., 2015b. La intermediación hipotecaria: la mejor opción contra ejecución hipotecaria. Revista Internacional de Estudios de Derecho Procesal y Arbitraje (RIEDPA) [en línea], no 2, pp. 1-27. Disponible en:

http://www.riedpa.com/COMU/documentos/RIEDPA21501.PDF [Con acceso el 4 de julio de 2018].

Callejo Carrión, S., y De Prada Rodríguez, M., 2016. Mediación y ejecución hipotecaria: ¿Una convivencia posible? En: I. Díez-Picazo Giménez y J. Vegas Torres, eds., Derecho, Justicia, Universidad. Liber Amicorum de Andres de la Oliva Santos. Madrid: Editorial Universitaria Ramón Areces, pp. 597-624.

Castillo Felipe, R., 2016. Mediación obligatoria y proceso de ejecución hipotecaria: una visión crítica. En: M. Espejo Lerdo de Tejada et al., eds., Vivienda, prestamo y ejecucion. Cizur Menor: Thomson Reuters Aranzadi, pp. 649-670.

Ceballos Peña, D., 2013. La mediación hipotecaria: un nuevo fenómeno de afrontamiento de conflictos en un entorno de crisis social. Revista de Mediación, no 12, 2ㅇ semestre.

Cobas Cobiella, M.E., 2014. La intermediación hipotecaria en sede de ejecuciones hipotecarias: luces y sombras sobre la cuestión. CEFLegal: revista práctica de derecho. Comentarios y casos prácticos, no 160, pp. 5-40.

Collins, J.M., y Urban, C., 2015. Mandatory Mediation Laws and the Renegotiation of Mortgage Contracts. The Economical Journal, 125(589), pp. 1734-1763.

Comisión Europea, 2011. National measures and practices to avoid foreclosure procedures for residential mortgage loans. Accompanying document to the Proposal for a Directive of the European Parliament and of the Council on credit agreements relating to residential property. SEC(2011) 357 final [en línea]. Documento de trabajo. Bruselas: Comisión Europea, 31 de marzo. Disponible en: https://eur-lex.europa.eu/legalcontent/EN/TXT/DOC/? Uri=CELEX:52011SC0357\&from=EN [Con acceso el 4 de julio de 2018]. 
Department for Business, Innovation \& Skills, 2014. Alternative dispute resolution for consumers. Implementing the Alternative Dispute Resolution Directive and Online Dispute Resolution Regulation [en línea]. Informe. 11 de marzo. Disponible en: https://assets. publishing. service.gov.uk/government/uploads/system/uploads Lattachment_data/file/288199/bis-14-575-implementing-alternative-disputeresolution-directive-and-online-dispute-resolution-regulation-consultation.pdf [Con acceso el 4 de julio de 2018].

Díez García, H., 2012. Recargas hipotecarias e hipotecas recargables. Madrid: Reus, pp. 18-71.

Embid Irujo, A., 2009. El Derecho de la crisis económica. Prensas Universitarias de Zaragoza.

Esteve Garcia, G., 2011. Las leyes autonómicas españolas: los conceptos básicos. En: M.E. Lauroba, ed., Materiales jurídicos del Libro Blanco de la mediación en Cataluña. Generalitat de Catalunya. Barcelona: Huygens, pp. 47-56.

European Commission for the Efficiency of Justice-CEPEJ 2014. European judicial systems. Edition 2014 (2012 data): Efficiency and quality of justice [en línea]. Estrasburgo: Consejo de Europa. Disponible en: https://rm.coe.int/europeanjudicial-systems-edition-2014-2012-data-efficiency-and-qualit/1680785d95 [Con acceso el 4 de julio de 2018].

García Montalvo, J., 2008. De la quimera inmobiliaria al colapso financiero. Crónica de un desenlace anunciado. Barcelona: Bosch.

García Montoro, L., 2015. "Nuevo" modelo de resolución alternativa de conflictos de consumo a la luz del Anteproyecto de Ley de Resolución Alternativa de Conflictos de Consumo. Especial referencia a las posibilidades de supervivencia de la mediación y otros mecanismos tradicionales. Revista CESCO de Derecho de Consumo, no 14, 1-27.

Ginebra Molins, M.E., y Tarabal Bosch, J., 2013. La obligatoriedad de la mediación derivada de la voluntad de las partes: las cláusulas de mediación. InDret [en línea], 4/2013, pp. 1-31. Disponible en:

http://www.indret.com/pdf/1016_es.pdf [Con acceso el 4 de julio de 2018].

Gutiérrez Santiago, P., 2015. Mecanismos "alternativos" frente al desahucio hipotecario de la vivienda habitual. Revista J urídica de la Universidad de León [en línea], no 2, pp. 3-69. Disponible en: https://docplayer.es/18155646Mecanismos-alternativos-frente-al-desahucio-hipotecario-de-la-viviendahabitual.html [Con acceso el 4 de julio de 2018].

Hagerott, J.C., 2012. Foreclosure mediation: responding to the current crisis. Capital University Law review [en línea], (40)899, pp. 899-934. Disponible en: http://law. capital.edu/WorkArea/DownloadAsset. aspx?id=27056 [Con acceso el 4 de julio de 2018].

Iturmendi, B., y Rodríguez Prieto, F., 2017. La evaluación en la mediación: una visión crítica. La Trama [en línea], no 52, febrero, pp. 1-12. Disponible en: http://fundacionsignum.org/wp-content/uploads/2017/03/Evaluacion-en-medvisi\%C3\%B3n-critica.pdf [Con acceso el 4 de julio de 2018].

Laparra, M., y Pérez Eransus, B., eds., 2012. Crisis y fractura social en Europa. Causas y efectos en España. Colección Estudios Sociales [en línea], № 35. Barcelona: Obra Social de La Caixa. Disponible en: https://multimedia.caixabank.es/lacaixa/ondemand/obrasocial/pdf/estudiosso ciales/vol35_es.pdf [Con acceso el 4 de julio de 2018].

Lauroba Lacasa, E., 2012. La Propuesta de Directiva del Parlamento Europeo y del Consejo sobre los Contratos de crédito relativos a los bienes inmuebles de uso 
residencial. En: E. Lauroba Lacasa, dir., y J. Tarabal Bosch, coord., Garantías reales en escenarios de crisis: presente y prospectiva. Madrid: Marcial Pons, pp. 117-132.

Lauroba Lacasa, E., et al., 2010. La construcción institucional y jurídica de la mediación. En: P. Casanovas, J. Magre y M.E. Lauroba, dirs., El libro blanco de la mediación en Cataluña [en línea]. Barcelona: Generalitat de Catalunya / Huygens, pp. 827-893. Disponible en: http://idtmagui.uab.cat/downloads/LibroBlanco.pdf [Con acceso el 4 de julio de 2018].

Libro verde de la Comisión [Europea], de 16 de noviembre de 1993, sobre el acceso de los consumidores a la justicia y solución de litigios en materia de consumo en el mercado único [en línea]. Disponible en: https://eurlex.europa.eu/legal-content/ES/TXT/HTML/?uri=LEGISSUM: I32023\&from=ES [Con acceso el 4 de julio de 2018].

Love, L.P., 1997. The Top Ten Reasons Why Mediators Should Not Evaluate. Florida State University Law Review [en línea], 24(5), pp. 937-948. Disponible en: http://ir.law.fsu.edu/Ir/vol24/iss4/5 [Con acceso el 4 de julio de 2018].

Marín López, M.J., 2008. Análisis del Real Decreto 231/2008, de 15 de febrero, que regula el Sistema Arbitral de Consumo [en línea]. Universidad de Castilla-La Mancha: Centro de Estudios de Consumo. Disponible en: https://previa.uclm.es/centro/cesco/pdf/trabajos/19/2008/19-2008-1.pdf [Con acceso el 4 de julio de 2018].

Marqués Cébola, C.S., 2013. La mediación. Barcelona: Marcial Pons.

Merelles Pérez, M., 2016. La mediación como requisito previo de admisión de la demanda. Diario La Ley, no 8682, pp. 1-4.

Nasarre Aznar, S., y Simón Moreno, H., 2015. Un paso más en la protección de los deudores hipotecarios de vivienda: la Directiva 2014/17/UE y la reforma del Código de Consumo de Cataluña por Ley 20/2014. Revista de Derecho Bancario y Bursátil, no 139, julio-septiembre, pp. 2-54.

Orozco Pardo, G., 2016. La mediación en los conflictos de consumo. Vlex, pp. 671696.

Pérez Daudí, V., 2015. Aspectos procesales de la mediación preceptiva en los procesos hipotecarios. Diario La Ley, no 8541, pp. 1-12.

Press, S., 1997. Institutionalization: Savior or Saboteur of Mediation? Florida State University Law Review [en línea], 24(4), pp. 903-917. Disponible en: http://ir.law.fsu.edu//r/vol24/iss4/3 [Con acceso el 4 de julio de 2018].

Quesada López, P.M., 2017. La integración de los medios de solución autocompositivos en el procedimiento de ejecución hipotecaria: problemática desde la perspectiva procesal y propuesta de fase prerrealizatoria. En: R. Cabrera Mercado, dir., y P.M. Quesada López, coord., La mediación como método para la resolución de conflictos. Madrid: Dykinson, pp. 195-223.

Ramos Méndez, F., ed., 2014. Hacia una gestión moderna y eficaz de la ejecución procesal. Barcelona: Atelier.

Recarte García-Andrade, A., 2008. La crisis financiera internacional y el crack financiero español. La Ilustración liberal, no 37, pp. 27-73.

Renuart, E., 2012. Toward a more equitable balance: homeowner and purchaser tensions in non-judicial foreclosure states. Loyola Consumer Law Review [en línea], vol. 24, pp. 562-585. Disponible en:

https://ssrn.com/abstract=2083795 [Con acceso el 4 de julio de 2018].

Riskin, L.L., 1994. Mediator orientations, strategies and techniques. Alternatives to the High cost of litigations (Center for Public Resources) [en línea], 12(9), pp. 
111-114. Disponible en: https://doi.org/10.1002/alt.3810120904 [Con acceso el 4 de julio de 2018].

Riskin. L.L., 1996. Understanding Mediators' Orientations, Strategies, and Techniques: A Grid for the Perplexed. Harvard Negotiation Law Review [en línea], 1(7), pp. 7-51. Disponible en:

http://scholarship.law.ufl.edu/facultypub/668 [Con acceso el 4 de julio de 2018].

Roberts, K.M., 2007. Mediating the Evaluative-Facilitative Debate: Why Both Parties Are Wrong and a Proposal for Settlement. Loyola University of Chicago Law Journal [en línea], 39(1), pp. 187-213. Disponible en: http://lawecommons. luc. edu/luclj/vol39/iss1/5 [Con acceso el 4 de julio de 2018].

Rodríguez López, J., 2014. Ejecuciones hipotecarias. Un año de la Ley 1/2013. Revista de Derecho Civil [en línea], no 3, pp. 105-120. Disponible en: https://www.nreg.es/ojs/index.php/RDC/article/viewFile/88/55 [Con acceso el 4 de julio de 2018].

Ruiz de La Fuente, C., 2014. La mediación en la ejecución hipotecaria: la experiencia de Ofideute. En: F. Ramos Méndez, ed., Hacia una gestión moderna y eficaz de la ejecución procesal. Barcelona: Atelier, pp. 357-365.

Sabatier, P., y Mazmanian, D., 1979. The conditions of effective implementation: A guide to accomplishing policy objectives. Policy Analysis, 5(4), pp. 481-504.

Sánchez Pos, M.V., 2012. La mediación y el proceso judicial civil (exposición de la Ley $5 / 2012$, de 6 de julio, de mediación en asuntos civiles y mercantiles, y de las reformas que introduce en la Ley de Enjuiciamiento Civil). En: F. Cordón Moreno y M.V. Sánchez Pos, eds., La Ley de Medidas de Agilizacion Procesal y la Ley de Mediacion: Exposicion de las Reformas Recientes de la Justicia Civil. Cizur Menor: Aranzadi, pp. 95-137.

Servicio Jurídico de la Unión Europea, 2013. Guía práctica común del Parlamento Europeo, del Consejo y de la Comisión para la redacción de textos legislativos de la Unión Europea [en línea]. 2a edición. Luxemburgo: Oficina de Publicaciones de la Unión Europea. Disponible en: https://publications. europa.eu/es/publication-detail/-/publication/3879747d7a3c-411b-a3a0-55c14e2ba732 [Con acceso el 4 de julio de 2018].

Shapira, O., 2016. A Theory of Mediators' Ethics. Foundations, Rationale, and Application. Cambridge University Press.

Sosa Wagner, F., y Fuertes López, M., 2011. Bancarrota del Estado y Europa como contexto. Madrid: Marcial Pons.

Stroie, I.R., 2017. Los Estados miembros pueden imponer un procedimiento de mediación como requisito de admisibilidad de una demanda judicial. STJUE (Sala Primera) de 14 de junio de 2017, asunto C-75/16 [en línea]. Universidad de Castilla-La Mancha: Centro de Estudios de Consumo. Publicaciones jurídicas, 20 de julio. Disponible en:

http://centrodeestudiosdeconsumo.com/images/ST]UE_mediacion_obligatoria. pdf [Con acceso el 4 de julio de 2018].

Tamayo Haya, S., 2010. La mediación aplicada al sobreendeudamiento del consumidor. En: L. García Villaluenga et al., eds., Mediación, arbitraje y resolución extrajudicial de conflictos en el siglo XXI. Vol. 1: Mediación. Madrid: Reus, pp. 243-260.

Tortella, G., y Núñez, C.E., 2009. Para comprender la crisis. Madrid: Gadir.

United Nations Conference on Trade and Development, 2010. Investor-State Disputes: Prevention and Alternatives to Arbitration. UNCTAD Series on 
International Investment Policies for Development [en línea]. Nueva York / Ginebra: Naciones Unidas. Disponible en:

http://unctad.org/en/docs/diaeia200911_en.pdf [Con acceso el 4 de julio de 2018].

Vall Rius, A., 2012. La intermediación en problemáticas hipotecarias. Revista Digital MM, no 2, diciembre pp. 1-17.

Vázquez de Castro, E., 2013. La solución negociada ante la ejecución hipotecaria. Revista Crítica de Derecho Inmobiliario, no 740, pp. 3973-4006.

Viladomat, R., 2017. Nou servei de mediació hipotecària a Santa Perpètua de Mogoda per evitar desnonaments [en línea]. 5 de mayo. Diputació de Barcelona. Disponible en: https://www.diba.cat/es/web/sala-de-premsa/Inou-servei-de-mediacio-hipotecaria-a-santa-perpetua-de-mogoda-per-evitardesnonaments [Con acceso el 4 de julio de 2018].

Vilalta, A.E., 2010. El marco jurídico: derecho comparado, En: P. Casanovas, J. Magre y M.E. Lauroba, dirs., El libro blanco de la mediación en Cataluña [en línea]. Barcelona: Generalitat de Catalunya / Huygens, pp. 129-178. Disponible en: http://idt-magui.uab.cat/downloads/LibroBlanco.pdf [Con acceso el 4 de julio de 2018].

Vilalta, A.E., 2014. Las reclamaciones de consumo en Cataluña y el sistema de mediación institucional (Análisis del Decreto 98/2014, de 8 de julio, sobre el procedimiento de mediación en las relaciones de consumo, a la luz de la normativa comunitaria y estatal). InDret [en línea], 4/2014, octubre, pp. 127. Disponible en: http://www.indret.com/pdf/1086. pdf [Con acceso el 4 de julio de 2018].

World Bank Group, 2011. Alternative Dispute Resolution Guidelines [en línea]. Washington, DC. Disponible en:

http://siteresources.worldbank.org/INTECA/Resources/15322_ADRG_Web.pdf [Con acceso el 4 de julio de 2018].

Referencias normativas

Unión Europea

Directiva 2000/31/CE del Parlamento Europeo y del Consejo, de 8 de junio de 2000, relativa a determinados aspectos jurídicos de los servicios de la sociedad de la información, en particular el comercio electrónico en el mercado interior (Directiva sobre el comercio electrónico). Diario Oficial [en línea], $\mathrm{n}$ o 178, de 17 de julio. Disponible en: https://eur-lex.europa.eu/legalcontent/ES/TXT/HTML/? uri=CELEX: 32000L0031\&from=ES [Con acceso el 4 de julio de 2018].

Directiva 2002/21/CE, del Parlamento Europeo y del Consejo, de 7 de marzo de 2002, relativa a un marco regulador común de las redes y los servicios de comunicaciones electrónicas (Directiva marco). Diario Oficial de las Comunidades Europeas [en línea], L 108/33, de 24 de abril. Disponible en: https://www. boe.es/doue/2002/108/L00033-00050.pdf [Con acceso el 4 de julio de 2018].

Directiva 2002/65/CE del Parlamento Europeo y del Consejo, de 23 de septiembre de 2002, relativa a la comercialización a distancia de servicios financieros destinados a los consumidores, y por la que se modifican la Directiva 90/619/CEE del Consejo y las Directivas 97/7/CE y 98/27/CE. Diario Oficial [en línea], $\mathrm{n}^{\circ} \mathrm{L} 271$, de 9 de octubre. Disponible en: https://eurlex.europa.eu/legal-content/ES/TXT/HTML/?uri=CELEX: 32002L0065\&from=ES [Con acceso el 4 de julio de 2018]. 
Directiva 2013/11/UE del Parlamento Europeo y del Consejo, de 21 de mayo de 2013, relativa a la resolución alternativa de litigios en materia de consumo y por la que se modifica el Reglamento (CE) no 2006/2004 y la Directive 2009/22/CE (Directiva sobre resolución alternativa de litigios en materia de consumo). Diario Oficial de la Unión Europea [en línea], L 165/63, de 18 de junio. Disponible en: https://www.boe.es/doue/2013/165/L00063-00079.pdf [Con acceso el 4 de julio de 2018].

Directiva 2014/17/UE del Parlamento Europeo y del Consejo, de 4 de febrero de 2014, sobre los contratos de crédito celebrados con los consumidores para bienes inmuebles de uso residencial y por la que se modifican las Directivas 2008/48/CE y 2013/36/UE y el Reglamento (UE) no 1093/2010. Diario Oficial de la Unión Europea [en línea], № 60, de 28 de febrero. Disponible en: https://www. boe.es/doue/2014/060/L00034-00085.pdf [Con acceso el 4 de julio de 2018].

Reglamento no 524/2013, del Parlamento Europeo y del Consejo de 21 de mayo de 2013 sobre resolución de litigios en línea en materia de consumo y por el que se modifica el Reglamento (CE) no 2006/2004 y la Directiva 2009/22/CE [también llamado Reglamento ODR de consumo]. Diario Oficial de la Unión Europea [en línea], L 165/1, de 18 de junio. Disponible en: https://www. boe.es/doue/2013/165/L00001-00012.pdf [Con acceso el 4 de julio de 2018].

Resolución del Consejo de la Comunidad Económica Europea de 25 de junio de 1987 sobre el acceso de los consumidores a la justicia. Diario Oficial de las Comunidades Europeas, no C 176, de 4 de julio, pp. 1-2.

España

Constitución Española de 1978. Boletín Oficial del Estado [en línea], №. 311, de 29 de diciembre de 1978. Disponible en:

https://www. boe.es/buscar/doc.php?id=BOE-A-1978-31229 [Con acceso el 4 de julio de 2018].

Ley 15/2015, de 2 de julio, de la Jurisdicción Voluntaria. Boletín Oficial del Estado [en línea], no 158, de 3 de julio. Disponible en:

https://www. boe.es/boe/dias/2015/07/03/pdfs/BOE-A-2015-7391.pdf [Con acceso el 4 de julio de 2018].

Ley $22 / 2010$, de 20 de julio, del Código de consumo de Cataluña. Boletín Oficial del Estado [en línea], no 196, de 13 de agosto. Disponible en: https://www. boe.es/boe/dias/2010/08/13/pdfs/BOE-A-2010-13115.pdf [Con acceso el 4 de julio de 2018].

Ley $36 / 2011$, de 10 de octubre, reguladora de la jurisdicción social. Boletín Oficial del Estado [en línea], no 245, de 11 de octubre. Disponible en: https://www. boe.es/buscar/doc.php?id=BOE-A-2011-15936 [Con acceso el 4 de julio de 2018].

Ley $5 / 2012$, de 6 de julio, de mediación en asuntos civiles y mercantiles. Boletín Oficial del Estado [en línea], no 162, de 7 de julio. Disponible en: https://www. boe.es/boe/dias/2012/07/07/pdfs/BOE-A-2012-9112.pdf [Con acceso el 4 de julio de 2018].

Ley $7 / 2017$, de 2 de noviembre, por la que se incorpora al ordenamiento jurídico español la Directiva 2013/11/UE, del Parlamento Europeo y del Consejo, de 21 de mayo de 2013, relativa a la resolución alternativa de litigios en materia de consumo. Boletín Oficial del Estado [en línea], o 268, de 4 de noviembre. Disponible en: https://www. boe.es/boe/dias/2017/11/04/pdfs/BOE-A-201712659.pdf [Con acceso el 4 de julio de 2018]. 
Ley Orgánica 6/2006, de 19 de julio, de reforma del Estatuto de Autonomía de Cataluña. Boletín Oficial del Estado [en línea], no 172, de 20 de julio de 2006. Disponible en: https://www.boe.es/buscar/doc.php?id=BOE-A-2006-13087 [Con acceso el 4 de julio de 2018].

Proyecto de Ley reguladora de los contratos de crédito inmobiliario, de 14 de noviembre de 2017. Boletín Oficial de las Cortes Generales. Congreso de los Diputados [en línea], 17 de noviembre. XII Legislatura. Disponible en: http://www. congreso.es/public oficiales/L12/CONG/BOCG/A/BOCG-12-A-121.PDF [Con acceso el 4 de julio de 2018].

Real Decreto 231/2008, de 15 de febrero, por el que se regula el Sistema Arbitral de Consumo. Boletín Oficial del Estado [en línea], no 48, de 25 de febrero. Disponible en: https://www. boe.es/boe/dias/2008/02/25/pdfs/A1107211086.pdf [Con acceso el 4 de julio de 2018].

Real Decreto Legislativo 1/2007, de 16 de noviembre, por el que se aprueba el texto refundido de la Ley General para la Defensa de los Consumidores y Usuarios y otras leyes complementarias. Boletín Oficial del Estado [en línea], no 287, de 30 de noviembre. Disponible en: https://www. boe.es/boe/dias/2007/11/30/pdfs/A49181-49215.pdf [Con acceso el 4 de julio de 2018].

Cataluña

Decreto 98/2014, de 8 de julio, sobre el procedimiento de mediación en las relaciones de consumo. Departamento de Empresa y Empleo de la Generalitat de Cataluña. Diario Oficial de la Generalitat de Cataluña, no 6661, de 10 de julio.

Ley 20/2014, de 29 de diciembre, de modificación de la Ley 22/2010, de 20 de julio, del Código de consumo de Cataluña, para la mejora de la protección de las personas consumidoras en materia de créditos y préstamos hipotecarios, vulnerabilidad económica y relaciones de consumo. Boletín Oficial del Estado [en línea], no 18, de 21 de enero de 2015. Disponible en: https://www. boe.es/boe/dias/2015/01/21/pdfs/BOE-A-2015-471.pdf [Con acceso el 4 de julio de 2018].

Ley $24 / 2015$, de 29 de julio, de medidas urgentes para afrontar la emergencia en el ámbito de la vivienda y la pobreza energética. Boletín Oficial del Estado [en línea], no 216, de 9 de septiembre. Disponible en: https://www. boe.es/boe/dias/2015/09/09/pdfs/BOE-A-2015-9725.pdf [Con acceso el 4 de julio de 2018].

Ley $4 / 2016$, de 23 de diciembre, de medidas de protección del derecho a la vivienda de las personas en riesgo de exclusión residencial. Boletín Oficial del Estado [en línea], № 15, de 18 de enero de 2017. Disponible en: https://www. boe.es/buscar/pdf/2017/BOE-A-2017-522-consolidado.pdf [Con acceso el 4 de julio de 2018].

Alemania

Insolvenzordnung vom 5. Oktober 1994 (BGBI. I S. 2866), die zuletzt durch Artikel 24 Absatz 3 des Gesetzes vom 23. Juni 2017 (BGBI. I S. 1693) geändert worden ist [en línea]. Disponible en: https://www. gesetze-iminternet. de/inso/B] NR286600994.html [Con acceso el 4 de julio de 2018].

J urisprudencia

Consejo General del Poder Judicial, 2010. Informe al Anteproyecto de Ley de mediación en asuntos civiles y mercantiles [en línea]. 19 de mayo. Disponible en:

http://www.poderjudicial.es/stfls/cgpj/COMISI\% C3\% 93N\% 20DE\% 20ESTUDIO 
S\% 20E\% 20I NFORMES/INFORMES\%20DE\% 20LEY/FICHERO/009.10_1.0.0.pdf [Con acceso el 4 de julio de 2018].

Sentencia del Tribunal de Justicia (Sala Cuarta) de 18 de marzo de 2010. Asuntos acumulados C-317/08 a C-320/08 (peticiones de decisión prejudicial planteadas por el Giudice di Pace di Ischia - Italia) - Rosalba Alassini/Telecom Italia SpA (C-317/08); Filomena Califano/Wind SpA (C318/08); Lucia Anna Giorgia Iacono/Telecom Italia Spa (C-319/08); Multiservice Srl/Telecom Italia SpA (C-320/08) (Petición de decisión prejudicial - Principio de tutela judicial efectiva - Redes y servicios de comunicaciones electrónicas - Directiva 2002/22/CE - Servicio universal Litigios entre usuarios finales y proveedores - Tentativa de conciliación extrajudicial obligatoria). Diario Oficial de la Unión Europea [en línea], C 134/3, de 22 de mayo de 2010. Disponible en: https://eurlex.europa.eu/legal-content/ES/TXT/?uri=CELEX\%3A62008CA0317 [Con acceso el 4 de julio de 2018].

Sentencia del Tribunal de Justicia (Sala Primera) de 14 de junio de 2017. Asunto C75/16, ECLI:EU: C: 2017: 457. 